\title{
Transient Tribo-Dynamics of Thermo-Elastic Compliant High-Performance Piston Skirts
}

\author{
B. Littlefair $\cdot$ M. De la Cruz $\cdot$ S. Theodossiades $\cdot$ \\ R. Mills $\cdot$ S. Howell-Smith $\cdot$ H. Rahnejat • \\ R. S. Dwyer-Joyce
}

Received: 5 July 2013/Accepted: 1 October 2013/Published online: 19 October 2013

(c) The Author(s) 2013. This article is published with open access at Springerlink.com

\begin{abstract}
Advanced piston technology for motorsport applications is driven through development of lightweight pistons with preferentially compliant short partial skirts. The preferential compliance is achieved through structural stiffening, such that a greater entrainment wedge is achieved at the skirt's bottom edge through thermo-elastic deformation, whilst better conforming contact geometry at the top of the skirt. In practice, the combination of some of these conditions is intended to improve the load-carrying capacity and reduce friction. The approach is fundamental to the underlying ethos of race and high-performance engine technology. Contact loads of the order of $5 \mathrm{kN}$ and contact kinematics in the range $0-35 \mathrm{~m} / \mathrm{s}$ result in harsh transient tribological conditions. Therefore, piston design requires detailed transient analysis, which integrates piston dynamics, thermo-elastic distortion and transient elastohydrodynamics. The paper provides such a detailed analysis as well as verification of the same using noninvasive ultrasonic-assisted lubricant film thickness measurement from a fired engine under normal operating conditions, an approach not hitherto reported in literature. Good agreement is noted between measured film thickness and predictions.
\end{abstract}

B. Littlefair - M. De la Cruz · S. Theodossiades .

H. Rahnejat ( $\bowtie)$

Wolfson School of Mechanical and Manufacturing Engineering,

Loughborough University, Loughborough, UK

e-mail: H.Rahnejat@lboro.ac.uk

R. Mills · R. S. Dwyer-Joyce

School of Mechanical Engineering, University of Sheffield,

Sheffield, UK

S. Howell-Smith

Capricorn Automotive Ltd., Basingstoke, UK
Keywords High-performance IC engines .

Compliant piston skirt - Thermo-elastic distortion .

Ultrasonic film thickness measurement - Transient

thermo-elastohydrodynamics

\section{List of symbols}

$a \quad$ In Reynolds' discretisation — contact half-length (m) Elsewhere-distance from gudgeon pin axis to piston crown (m)

$b \quad$ In Reynolds' discretisation-contact half-width (m) Distance from piston's centre of mass to piston crown (m)

$c \quad$ Nominal clearance (m)

$C_{\mathrm{c}} \quad$ Crankshaft offset (m)

$C_{\mathrm{g}} \quad$ Centre of gravity offset (m)

$C_{\mathrm{pb}} \quad$ Gudgeon pin offset (m)

$C_{\mathrm{p}}$ Combined gudgeon pin and crankshaft offset $\left(C_{\mathrm{p}}=C_{\mathrm{pb}}+C_{\mathrm{c}}\right)(\mathrm{m})$

$e_{\mathrm{b}} \quad$ Clearance between bottom end of piston skirt and cylinder liner $(\mathrm{m})$

$e_{\mathrm{t}} \quad$ Clearance between top end of piston skirt and cylinder liner $(\mathrm{m})$

$E^{\prime} \quad$ Reduced Young's modulus

$f_{\text {con }} \quad$ Connecting rod force $(\mathrm{N})$

$f_{\mathrm{g}} \quad$ Gas force $(\mathrm{N})$

$f_{\mathrm{gg}} \quad$ Inertial force of gudgeon due to primary motion $(\mathrm{N})$

$f_{\mathrm{gp}} \quad$ Inertial force of piston due to primary motion (N)

$f_{\mathrm{ig}} \quad$ Inertial force of gudgeon due to secondary motion $(\mathrm{N})$

$f_{\text {ip }} \quad$ Inertial force of piston due to secondary motion (N)

$f_{\mathrm{r} 1} \quad$ Reaction force at skirt's anti-thrust side $(\mathrm{N})$

$f_{\mathrm{r} 2} \quad$ Reaction force at skirt's thrust side $(\mathrm{N})$

$f_{\mathrm{s}} \quad$ Side load due to connecting $\operatorname{rod}(\mathrm{N})$

$h \quad$ Oil film thickness (m)

$i \quad$ Nodal location on skirt-axial direction (m) 
$j \quad$ Nodal location on skirt-circumferential direction (m)

$I_{\mathrm{p}} \quad$ Inertia of piston $\left(\mathrm{kg} \mathrm{m}^{2}\right)$

$l \quad$ Connecting rod length $(\mathrm{m})$

$L \quad$ Skirt height $(m)$

$m_{\mathrm{g}} \quad$ Mass of gudgeon pin $(\mathrm{kg})$

$m_{\mathrm{p}} \quad$ Mass of piston $(\mathrm{kg})$

$M_{\text {con }} \quad$ Moment due to crankshaft offset (Nm)

$M_{\text {fr1 }} \quad$ Moment due to anti-thrust's reaction force (Nm)

$M_{\mathrm{fr} 2} \quad$ Moment due to thrust's reaction force (Nm)

$M_{\mathrm{s}} \quad$ Moment due to assembly's offsets (Nm)

$n x x \quad$ Number of nodes along discretised skirt along the $x$-direction

nyy Number of nodes along discretised skirt along the $y$-direction

$p \quad$ Hydrodynamic pressure $(\mathrm{Pa})$

$p_{1} \quad$ Hydrodynamic pressure on anti-thrust side $(\mathrm{Pa})$

$p_{2} \quad$ Hydrodynamic pressure on thrust side $(\mathrm{Pa})$

$P \quad$ Cylinder pressure (bar)

$P_{\mathrm{b}} \quad$ Pressure resulting from asperity interactions $(\mathrm{Pa})$

$P_{\mathrm{h}} \quad$ Non-dimensionalisation reference pressure $(\mathrm{Pa})$

$P_{\text {ref }} \quad$ Reference pressure $(\mathrm{Pa})$

$P_{\mathrm{v}} \quad$ Viscous/hydrodynamic pressure $(\mathrm{Pa})$

$r \quad$ Crankshaft radius (m)

$r_{\mathrm{p}} \quad$ Piston radius (m)

$R_{\mathrm{x}} \quad$ Equivalent radius of curvature (m)

$t \quad$ Time $(s)$

$u \quad$ Speed of entraining motion $\left(\mathrm{ms}^{-1}\right)$

$u_{\mathrm{av}} \quad$ Average speed used for non-dimensionalisation $\left(\mathrm{ms}^{-1}\right)$

$v_{1} \quad$ Side leakage $\left(\mathrm{ms}^{-1}\right)$

$W \quad$ Non-dimensionalisation reference load $(N)$

$x \quad$ In Reynolds' equation-direction of entraining motion (m)

In piston kinematics—-primary piston displacement (m)

$\ddot{x}_{\text {ref }} \quad$ Reference acceleration $\left(\mathrm{ms}^{-2}\right)$

$y \quad$ In Reynolds' equation — direction of side leakage $(m)$

$\alpha \quad$ Pressure-viscosity index $\left(\mathrm{Pa}^{-1}\right)$

$\beta \quad$ Piston's rigid tilt angle (rad)

$\beta^{\prime} \quad$ Thermal expansion coefficient of lubricant $\left(\mathrm{K}^{-1}\right)$

$\varepsilon_{\mathrm{p}} \quad$ Pressure convergence criteria (-)

$\eta \quad$ Viscosity (Pa s)

$\theta \quad$ Crankshaft torsional displacement $(\mathrm{rad})$

$\rho \quad$ Density $\left(\mathrm{kg} \mathrm{m}^{-3}\right)$

$\phi \quad$ Connecting rod angle

$\varphi_{\mathrm{j}} \quad$ Circumferential location along the skirt (rad)

$\omega \quad$ Crankshaft angular velocity $\left(\mathrm{rad} \mathrm{s}^{-1}\right)$

$\Omega \quad$ Pressure relaxation parameter (-)

\section{Subscripts}

$o$ Denotes at ambient temperature and pressure

$p$ Integrator time step number in linear acceleration method (-)

$q$ Iteration step in linear acceleration method (-)

\section{Superscripts}

- First time derivative $\left(\mathrm{s}^{-1}\right)$

.. Second time derivative $\left(\mathrm{s}^{-2}\right)$

\section{Introduction}

Frictional losses in the piston skirt-cylinder liner conjunction account for approximately $3 \%$ of the input fuel energy, whereas piston ring pack losses account for a further $4 \%$ [11]. These losses are primarily due to viscous shear of the lubricant film and asperity interactions of contiguous surfaces. However, for most of the piston cycle, the regime of lubrication in the skirt-cylinder liner conjunction is dominated by hydrodynamic or soft elastohydrodynamic (iso-viscous elastic) regimes of lubrication [2, 16]. Therefore, aside from piston reversals at top and bottom dead centres, where mixed regime of lubrication can ensue, friction is usually generated through viscous shear of a lubricant film. Consequently, it has generally been surmised that reducing the lubricant viscosity would improve engine efficiency. However, the limiting factor is the lubricant load-carrying capacity in conjunctions with relatively high load intensity, such as the cam-follower contact [17]. Alternatively, a smaller piston skirt area would decrease friction as any boundary interaction is a function of the contact area. Through increased contact pressures, one may encourage piezo-viscous action of the lubricant, leading to elastohydrodynamic conditions, which would yield the lowest friction [12,35].

Lightweight aluminium pistons are seen more frequently in high-performance race engines as opposed to the OEM engines. They generally exhibit a more flexible contact area between the skirt and the liner. This is, however, usually at the expense of their operational life expectancy, because of the large distortions seen and the potential of ensuing fatigue. The growing emphasis on the reduction in the reciprocating mass and the increased demands brought by downsizing (with the resulting increase in the break mean effective pressure-BMEP) have a significant effect on the loads that the piston skirt needs to support. This has affected the deformed operating profile of contiguous solids, and therefore the contact conditions. Realistic prediction of these effects upon the mechanism of lubrication is the key to the ongoing developments for high-performance piston systems. In order to combine the effect of the aforementioned parameters throughout an engine cycle, a transient tribo-dynamic analysis is required. There is a dearth of reported research in this area with regard to the compliant race engine technology.

$\mathrm{Li}$ et al. [18] reported a transient hydrodynamic analysis of piston skirt. In particular, they studied the effects of 
lubricant viscosity and gudgeon pin offset on the overall friction. Knoll and Peeken [15] produced a similar study for the effects of piston offset on the generated tilting moments and maximum generated pressures. These works were confined to a rigid hydrodynamic analysis.

Zhu et al. [42, 43] presented a two-part analysis. In the first part, they developed transient hydrodynamics of rigid bodies in contact. The second part extended the approach to include gross piston distortions. They overcame the computation burden of the repeated time-dependent calculations for piston skirt deflection through use of an influence coefficient matrix, derived from their own FEA model [43]. Common to both their contributions was the use of low relaxation Newton-Raphson iterative solution for system dynamics. McFadden and Turnbull [22] presented a model of secondary piston motions and used it for cases of differing skirt profiles. They calculated the piston's primary motion dynamically using a reduced, coupled, spring and damper system. They illustrated the effect of in-cycle variable crank speed in a single-cylinder engine, though the analysis was limited to very low combustion pressures and, as such, relatively low side loads. Zhang et al. [41] demonstrated the effect of system inertia (including the connecting rod contribution) on the generated side forces. The dynamics of the system were solved using a fifth-order Runge-Kutta algorithm. Another solution with realistic combustion forces was presented by Perera et al. [28] who also included the effect of crank offset, using a flexible multi-body dynamics' approach in their transient analysis with Gear-Stiff integration algorithm. However, although the effect of temperature on the lubricant film thickness was taken into account with realistic side forces, the tribological contacts of the skirt-liner and piston ring pack were considered as rigid hydrodynamic. Offner and Priebsch [27] also used a flexible multi-body model to simulate the lubricated impact and frequency response of the piston-cylinder bore. They showed, parametrically, the effects of varying the lubricant grade and the nominal clearance on the maximum generated hydrodynamic pressures. Balakrishnan and Rahnejat [2] undertook a transient dynamics analysis at high loads and speeds, but with only localised contact deflection in their skirt-liner elastohydrodynamic analysis.

D'Agostino et al. [5] developed a transient elastohydrodynamic model, employing a multi-grid approach for the solution of Reynolds equation with finite element analysis for piston skirt deflection. This approach can be computationally inefficient, as it employs a large influence coefficient matrix for a set of linear equations. However, the use of multi-thread synchronised calculations for the two opposing skirt sides yielded a significant gain in terms of computational efficiency.

McClure [21] and McClure and Tian [20] developed a thermo-elastic transient routine, capturing the effect of moment contributions generated by the piston skirt conjunctional friction. They also included a simple model for pin-bore interactions. They employed a compliance matrix in a similar manner to that of Littlefair et al. [19]. The work of McClure was developed further by Bai [1] to include a more accurate description of contact surface, using the average flow solution of Reynolds equation with limited oil availability. Partial verification was shown qualitatively using the laser-induced fluorescence (LIF) technique. Ning et al. [26] followed an approach similar to that of Li et al. [18], but included the effect of flexibility and friction moments in a transient analysis. The compliance array generated for the skirt was based on a linear system and applied in a similar way to that of Bai [1] and McClure [21], but somewhat oversimplifying the loading condition in the piston FEA model.

Overall, the importance of piston skirt shape is well understood, and the features are "optimised" to account for the differential thermal expansion, whilst still offering adequate entraining geometries. The in-service shape is much harder to control as this emerges as a result of various mechanical distortions. Recently, Hoshikawa et al. [13] showed, through experimental techniques, the effect of stiffness variations and compared it with the analysis on frictional changes using a floating liner set-up. Qualitative observations from a visual liner were also made. Bai [1] also showed the effect of modifying the structural stiffness of the skirt using techniques detailed earlier by McClure [21]. The effects of varying the piston's structural stiffness on contact conditions, film shape and generated pressures were discussed. Partial verification was reported through laser-induced fluorescence (LIF) observations of the contact, which gave a rough qualitative comparison in terms of clearance and film shape. A quantitative comparison was made by Dwyer-Joyce et al. [9] using a single ultrasonic sensor, which showed good agreement between the measured film thickness and the predictive transient analysis, although a full 2D film thickness measurement and validation was not conducted.

Before a good estimate of friction in an engine cycle can be made, the regime of lubrication should be ascertained in a transient thermo-elastohydrodynamic analysis, which takes into account salient practical features such as thermoelastic distortion of the piston skirt. The prerequisite step in this quest is accurate prediction of film thickness throughout the engine cycle and validation of the methodology against precise measurement of film thickness. This is the area where hitherto lack of research findings is the most poignant. This paper is an attempt to overcome this particular shortcoming through combined non-invasive ultrasonic-assisted measurement of lubricant film thickness and transient thermo-elastohydrodynamics of a thermo-elastically distorted compliant piston skirt-liner conjunction for 
a high-performance motocross race engine. The ultrasonic film thickness measurement technique used here is based on the same overall principles as that reported in DwyerJoyce et al. [9]. However, the measurement resolution is much enhanced by fabrication of an array of ultrasonic sensors of considerably smaller size. It is important to note that coarser sensor dimensions, such as that reported in Dwyer-Joyce et al. [9], provide only an average film thickness over their actual physical dimension. Furthermore, measurement with a single sensor provides a time history of the film thickness as the piston traverses past the sensor's position. Hence, the film profile is not representative of a given instantaneous film shape and can lead to erroneous film shape determination by secondary motion of the piston. These shortcomings are overcome with the use of an array of fine-resolution sensors, but with the drawback of much more complex data acquisition and data processing.

\section{Experimental Set-Up}

A number of techniques have been developed and documented for measuring film thickness within IC engines. Laser-induced fluorescence (LIF) documented by Inagaki et al. has been used [14], inductance techniques by Taylor and Evans [38] and finally a capacitance approach by Söchting and Sherrington [36]. Each of these techniques needs to invasively modify (to varying degrees) the structural components for the installation of sensing elements. Thermal and load-generated deformation may then be affected, and differences in local tribological conditions may inadvertently be introduced.

By generating ultrasound on the exterior surface of the cylinder liner which is reflected back from the bore surface, the parent material of the liner remains unaltered. The conditions at the contact between bore and piston, however, affect the properties of the reflected wave. A brief overview of the ultrasonic technique used is provided here. However, the reader is directed to Mills et al. [23] for a more detailed account of the methodology.

When a planar ultrasonic wave strikes an interfacial boundary between different media of acoustically different property, a portion of the energy is transmitted whilst the remainder is reflected. The term reflection coefficient, $R$, gives the relative amplitudes of transmitted and reflected waves and for a perfectly bonded interface can be written as:

$R=\frac{Z_{1}-Z_{2}}{Z_{1}+Z_{2}}$

where $Z_{1}$ and $Z_{2}$ are the acoustic impedances of the interfacial boundary materials. For the case of a thin layer $(h \ll \lambda)$ present between the two bounding materials,
Tattersall [37] modelled the situation as a complex, quasistatic spring model in which the layer stiffness, $K$, is a function of the layer properties:

$R=\frac{\left(Z_{1}-Z_{2}\right)+i 2 \pi f_{\mathrm{u}}\left(\frac{Z_{1} Z_{2}}{K}\right)}{\left(Z_{1}+Z_{2}\right)+i 2 \pi f_{\mathrm{u}}\left(\frac{Z_{1} Z_{2}}{K}\right)}$

where $f_{\mathrm{u}}$ is the frequency of the ultrasonic wave. DwyerJoyce et al. [10] identified that the layer stiffness for a thin fluid layer would be governed by its thickness and compressibility. For the case of identical boundary materials $\left(Z_{1}=Z_{2}=Z\right)$, Eq. (3) can be used to relate film thickness to reflection coefficient, given the fluid layer acoustic velocity, $c$, and density, $\rho$ :

$h=\frac{2 \rho c^{2}}{\omega Z} \sqrt{\frac{R^{2}}{1-R^{2}}}$

Ultrasonic measurements were carried out using a modified, normally aspirated, spark ignition, Honda CRF 450R motocross engine mounted on an Oswald $250 \mathrm{~kW}$ dynamometer, specifically performed for this study. The configuration and principal geometry of the engine used are listed in Table 1.

It incorporates a modified wet liner and barrel assembly, allowing the installation of thermocouples and ultrasonic sensors. The set-up also features a specifically manufactured

Table 1 Basic engine parameters

\begin{tabular}{ll}
\hline Bore & $96 \mathrm{~mm}$ \\
Stroke & $62 \mathrm{~mm}$ \\
Conrod length & $107 \mathrm{~mm}$ \\
Capacity & $449 \mathrm{cc}$ \\
Nominal skirt-liner clearance & $15-25 \mu \mathrm{m}$ \\
Operating speed range & $3,000-10,000 \mathrm{rpm}$ \\
Maximum power & $41 \mathrm{~kW}$ at $9,000 \mathrm{rpm}$ \\
Maximum torque & $49.8 \mathrm{Nm}$ at $7,000 \mathrm{rpm}$ \\
\hline
\end{tabular}

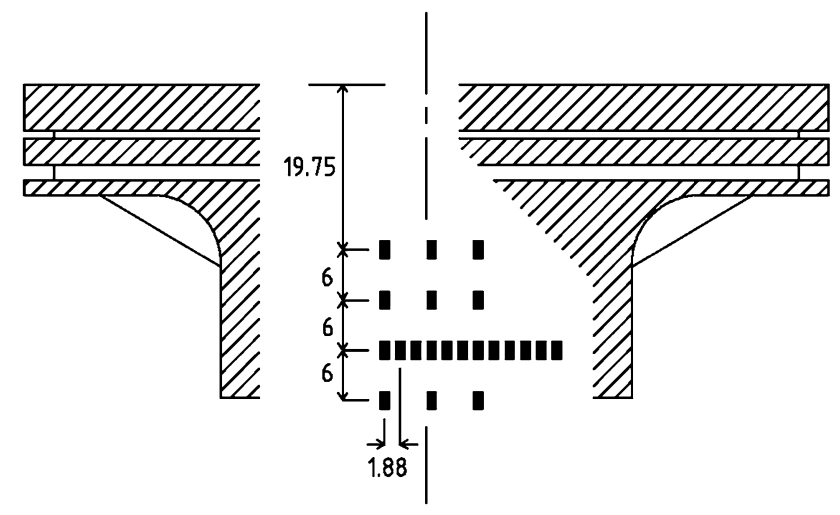

Fig. 1 Sensors' positions on the cylinder liner with overlaid piston (at the TDC) 


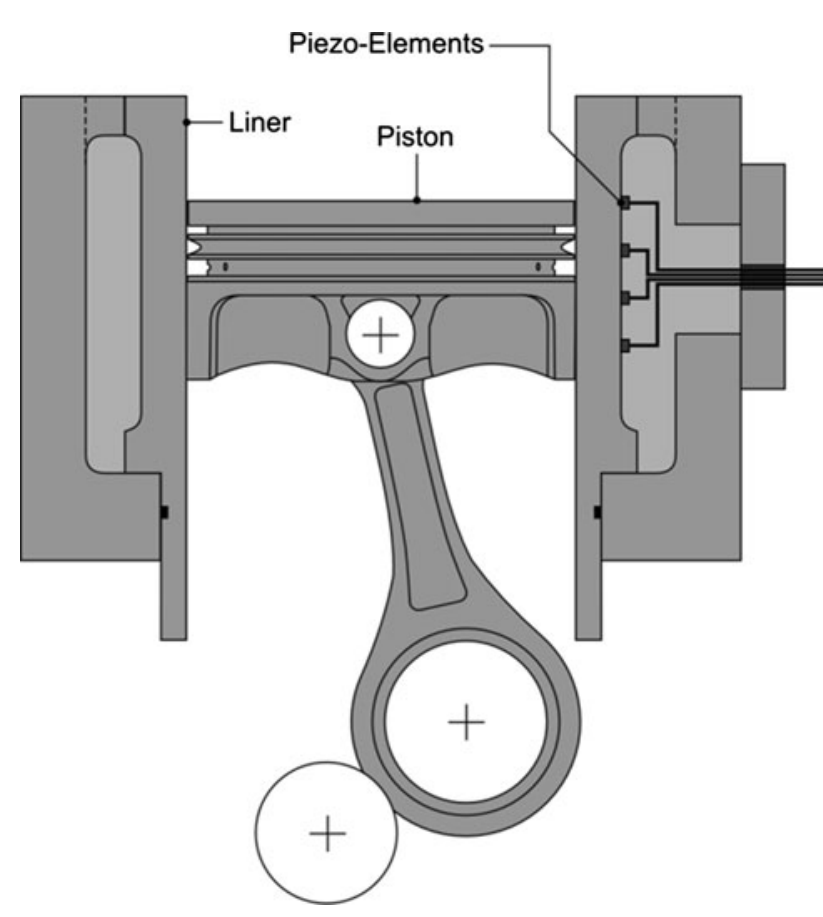

Fig. 2 Schematic view of liner instrumentation positioned over the thrust face of the skirt

piston common to both the experimental set-up and numerical predictions. Measurements of lubricant film thickness over the skirt contact area were carried out using a 2D array of ultrasonic transducers (21 piezoelectric elements of dimensions $2 \times 1 \mathrm{~mm}$ ) located according to Fig. 1 projected onto the thrust skirt face.

To facilitate adhesion of the transducers, a series of small flats were machined onto the exterior surface (water jacket boundary) of the water-cooled cylinder liner. The elements were sealed using silicone and the cabling routed through an orifice in the cylinder barrel as illustrated in Fig. 2. Mills et al. [23] outline the instrumentation procedure in detail.

The piezoelectric elements used for this test were pulsed at their centre frequency of $10 \mathrm{MHz}$. The pulses were generated and received in pulse-echo mode, using a PC-mounted ultrasonic pulse receiver. Pulses were generated at a rate of $80 \mathrm{k} \mathrm{pulse} / \mathrm{s}$, and the local portion of the reflection was digitised at $100 \mathrm{M}$ samples/s. The region of the signal corresponding to the first liner-skirt reflection was windowed and stored to a hard disk drive with the corresponding crank angle position obtained from a crank-mounted, 360-count encoder. A remotely operated multiplexer was used to switch between the active elements. Each element was pulsed for a period of $2 \mathrm{~s}$ before switching to the next. A total of between 70 and 120 engine cycles were captured at each sensor position over the engine speeds tested. The presented results are therefore the mean lubricant film thickness obtained from multiple cycles.
Prior to measuring lubricant film thickness, a liner instrumented with $8 \mathrm{k}$-type thermocouples was used to provide an axial temperature distribution along the accessible region of the liner. The thermocouples were positioned $0.8 \mathrm{~mm}$ from the internal surface of the liner. During testing, it was found that the internal surface of the cylinder was typically $30{ }^{\circ} \mathrm{C}$ hotter than the exiting coolant temperature. The operational temperatures were used to obtain the acoustic properties of the lubricant during the test (the oil having been characterised using an oven prior to testing).

The spectral content of the reflected pulses was extracted using fast Fourier transform (FFT) and the reflection coefficient obtained by normalising the measured spectral content with that from a reference pulse. The term reference pulse refers to the condition of total internal reflection of the ultrasound pulse. This essentially occurred when a gas interface was present at the liner surface. The reference condition was obtained during periods when the position of the piston was away from the location of the sensors. By continually updating the reference reflection, temperatureinduced transducer drifts could be eliminated. The measured reflection coefficient was then used to calculate film thickness using Eq. (3).

\section{Numerical Model}

\subsection{Dynamic and Kinematic Analysis}

To adequately replicate the physics of motion of the pistonconnecting rod-crankshaft assembly, the inertial dynamics of the system must be addressed. It is necessary to derive the equations of motion of the system, comprising piston primary and secondary motions.

Figure 3 is a free-body representation of system dynamics [12]. The forces and moments are depicted, together with overall geometry, reference planes and notation.

The primary motion of the piston (in the $x$-direction in Fig. 3) is treated as kinematic, governed by the instantaneous rotational motion of the crankshaft. However, the secondary motion (in the z-direction in Fig. 3) of the piston is more complex dynamic problem, confined within its radial clearance $(x-z$ plane). The inherent change in the connecting rod angle, combined with the effect of gudgeon pin and/or crankshaft offsets and the varying combustion pressure and rotational speed, induces transient secondary motions of the piston within the confine of its clearance (z-direction lateral excursion and the tilting motion $\beta$ ).

The equations describing the secondary motion of the piston are presented below [2, 12]: 


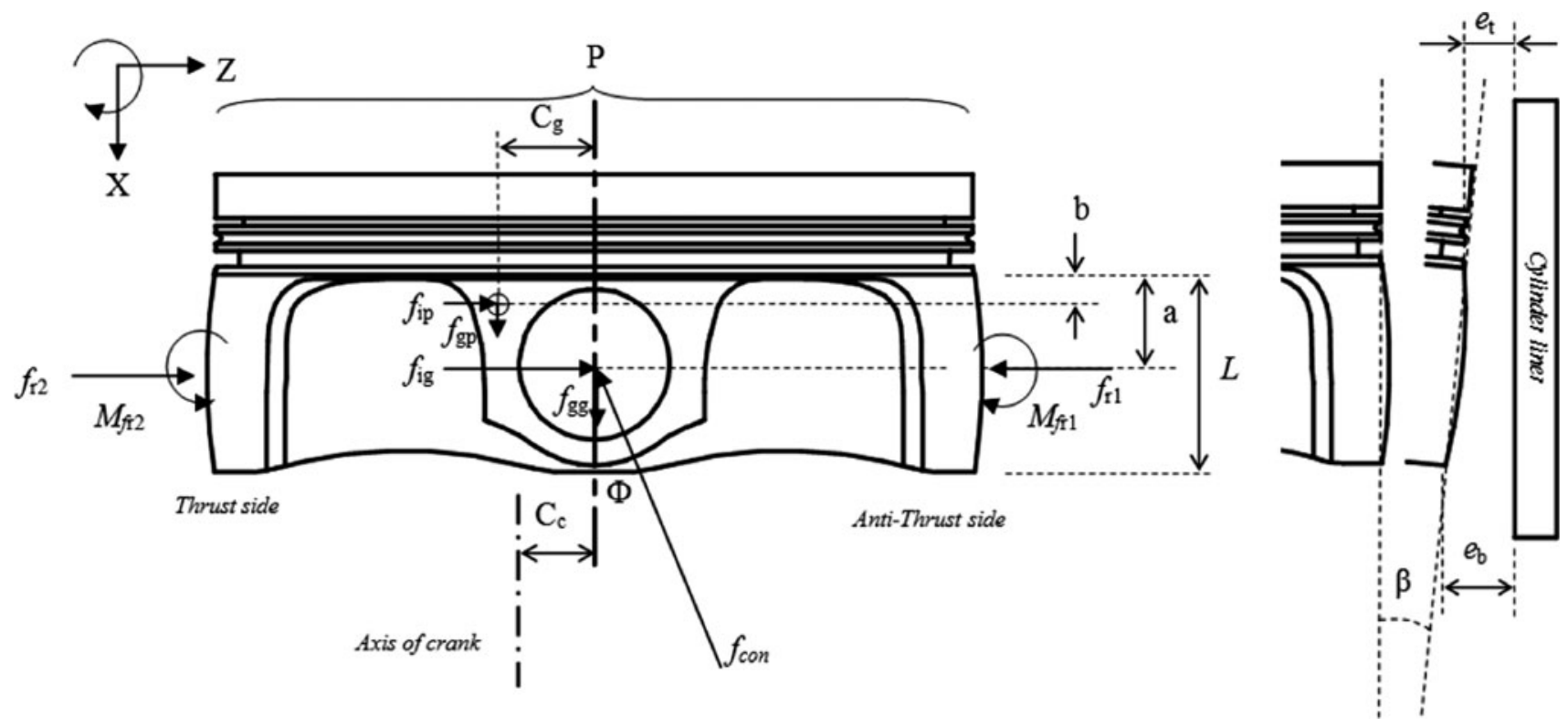

Fig. 3 Schematic free-body diagram of piston (including forces, clearances, dimensions and frame of reference)

$$
\begin{aligned}
& {\left[\begin{array}{ll}
m_{\mathrm{g}}\left(1-\frac{a}{L}\right)+m_{\mathrm{p}}\left(1-\frac{b}{L}\right) & m_{\mathrm{g}} \frac{a}{L}+m_{\mathrm{p}} \frac{b}{L} \\
\frac{I_{\mathrm{p}}}{L}+m_{\mathrm{p}}(a-b)\left(1-\frac{b}{L}\right) & m_{\mathrm{p}}(a-b) \frac{b}{L}-\frac{I_{\mathrm{p}}}{L}
\end{array}\right]\left[\begin{array}{l}
\ddot{e}_{\mathrm{t}} \\
\ddot{e}_{\mathrm{b}}
\end{array}\right]} \\
& =\left[\begin{array}{l}
f_{\mathrm{r} 1}+f_{\mathrm{r} 2}+f_{\mathrm{s}} \\
M_{\mathrm{fr} 1}+M_{\mathrm{fr} 2}+M_{\mathrm{s}}
\end{array}\right]
\end{aligned}
$$

Referring back to the primary motion of the piston assembly, the kinematics are derived as:

$l \sin \phi=C_{\mathrm{p}}+r \sin \theta$

where $C_{\mathrm{p}}$ is modified for the inclusion of the crank offset using $\left(C_{\mathrm{p}}=C_{\mathrm{pb}}+C_{\mathrm{c}}\right)$.

The inherently unbalanced nature of single cylinder and sharp changes in contact kinematics post-combustion result in inertial dynamics that are quite different to those described by idealised conditions and used routinely in piston dynamics. These are particularly important practical features of low rotational inertia high-performance race engines, subject of the current paper. After some manipulation and accounting for the effect of engine order vibrations [2, 33] and Littlefair et al. [19], the kinematic displacement, velocity and acceleration are obtained as ("Appendix 1" for $A$ and $B$ coefficients):

$x=r\left(A_{0}+A_{1} \cos \theta+A_{2} \cos 2 \theta+B_{1} \sin \theta+B_{3} \sin 3 \theta\right)$

$\dot{x}=-r \omega\left(A_{1} \sin \theta+2 A_{2} \sin 2 \theta-B_{1} \cos \theta-3 B_{3} \cos 3 \theta\right)$

$\ddot{x}=-r \omega^{2}\left(A_{1} \cos \theta+4 A_{2} \cos 2 \theta+B_{1} \sin \theta+9 B_{3} \sin 3 \theta\right)$
Equations (6) and (7) are plotted in Fig. 4, where maximum piston speed is around $18.2 \mathrm{~m} / \mathrm{s}$ and the stroke is $62 \mathrm{~mm}$ for the engine speed of 4,250 rpm.

\subsection{Lubrication Analysis}

The forces acting on the piston $\left(f_{\mathrm{r} 1}, f_{\mathrm{r} 2}, f_{\mathrm{s}}\right)$ are required for the dynamics of the system, where $f_{\mathrm{s}}$ is given as:

$f_{\mathrm{s}}=\left(\left(P \pi r_{\mathrm{p}}^{2}\right)+\left(m_{\mathrm{g}}+m_{\mathrm{p}}\right) \ddot{x}\right) \tan \phi$

Particular attention should be paid when approximating the values of the skirt reaction forces on the thrust $f_{\mathrm{r} 2}$ and anti-thrust sides $f_{\mathrm{r} 1}$. The instantaneous conjunctional characteristics for the lubricated contacts on the thrust and anti-thrust sides can be described using Reynolds' equation, which in its most generic form is:

$$
\begin{aligned}
\frac{\partial}{\partial x} & \left(\frac{\rho h^{3}}{\eta} \frac{\partial p}{\partial x}\right)+\frac{\partial}{\partial y}\left(\frac{\rho h^{3}}{\eta} \frac{\partial p}{\partial y}\right) \\
& =12\left(\frac{\partial}{\partial x}[\rho h u]+\frac{\partial}{\partial y}\left[\rho h v_{l}\right]+\frac{\mathrm{d}(\rho h)}{\mathrm{d} t}\right)
\end{aligned}
$$

The short piston skirt has a height-to-width ratio of around 1:1.8; thus, a two-dimensional form of Reynolds equation is used. Given the transient nature of the problem, it is necessary to retain the squeeze film effect (i.e. the lubricant film history, $\mathrm{d} h / \mathrm{d} t$ ). However, an assumption of no side leakage of lubricant in the circumferential direction is reasonable to be made, thus $v_{1}=0$. 
Fig. 4 Piston displacement and velocity at $4,250 \mathrm{rpm}$ engine speed (primary axial motion)

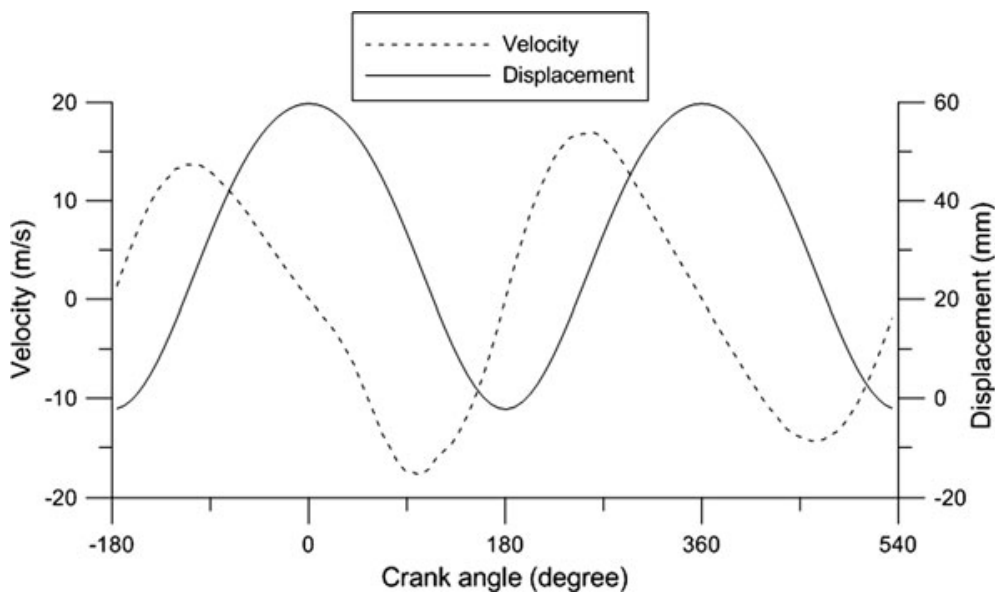

Given that the cylinder liner remains stationary, the speed of lubricant entraining motion is half that of piston's sliding velocity, thus

$u=\dot{x} / 2$

Following the results obtained from the instrumented cylinder liner, the temperature of the lubricant in the contact is assumed to be that of the liner surface at $110{ }^{\circ} \mathrm{C}$. In practice, the lubricant temperature is slightly higher than that of the liner on account of small temperature rise due to viscous shear through the contact. Morris et al. [24] used an analytical control volume method to determine the average temperature rise in the lubricant in passage through the contact for a very similar engine. They showed that the rise in lubricant temperature above that of the liner is small compared with the liner temperature, and thus the inlet lubricant temperature. Therefore, the assumption for lubricant temperature made here is quite reasonable. The variation in viscosity with applied pressure is given by Roelands' [34] equation as:

$\eta=\eta_{o} e^{\alpha}$

where $\eta_{\mathrm{o}}$ is the lubricant dynamic viscosity at the temperature of $110^{\circ} \mathrm{C}$, and $\alpha=\left(\ln \eta_{o}+9.67\right)\{[1+p /(1.98 \times$ $\left.\left.\left.10^{8}\right)\right]^{Z}-1\right\} / p$ and $Z=\alpha_{o} /\left[5.1 \times 10^{-9}\left(\ln \eta_{o}+9.67\right)\right]$

The density variation follows the relationship proposed by Dowson and Higginson [8] and Yang et al. [40]:

$\rho=\rho_{o}\left(1+\frac{0.6 \times 10^{-9} p}{1+1.7 \times 10^{-9} p}\right)\left[1-\beta^{\prime} \Delta T\right]$

where $\Delta T$ is the conjunctional temperature difference with respect to ambient conditions and $\beta^{\prime}$ is the lubricant's thermal expansion coefficient.

The hydrodynamic pressure distribution obtained from Reynolds' equation can then be integrated, allowing for the estimation of the reaction loads acting on the skirt on the thrust and anti-thrust sides as: $f_{\mathrm{r} 1 / 2}=\sum_{i=1}^{n x x} \sum_{j=1}^{n y y} p_{1 / 2} \mathrm{~d} x \mathrm{~d} y$

Since the moments are taken around the gudgeon pin axis (13 mm from the top of the skirt), each side of the skirt (thrust and anti-thrust) produces positive and negative moments. The size of the skirt is $27 \times 47 \mathrm{~mm}$. The moments are always computed along its entire circumferential width $(47 \mathrm{~mm})$. However, along the axial direction, these split around the gudgeon pin location (i.e. from 1 to $13 \mathrm{~mm}$ and from 14 to $27 \mathrm{~mm}$ ). Therefore, a constant distance $\left(d_{\mathrm{c}}\right.$-in metres) is used to identify this location and compute the moments accordingly. The net moments are obtained as:

$$
\begin{aligned}
M_{\mathrm{fr} 1}= & -\sum_{i=1}^{13} \sum_{j=1}^{47} p_{1}\left(d_{\mathrm{c}}-i\right) \cos \varphi_{j} \mathrm{~d} x \mathrm{~d} y \\
& +\sum_{i=14}^{27} \sum_{j=1}^{47} p_{1}\left(i-d_{\mathrm{c}}\right) \cos \varphi_{j} \mathrm{~d} x \mathrm{~d} y \quad \text { and } \\
M_{\mathrm{fr} 2}= & \sum_{i=1}^{13} \sum_{j=1}^{47} p_{2}\left(d_{\mathrm{c}}-i\right) \cos \varphi_{j} \mathrm{~d} x \mathrm{~d} y \\
& -\sum_{i=14}^{27} \sum_{j=1}^{47} p_{2}\left(i-d_{\mathrm{c}}\right) \cos \varphi_{j} \mathrm{~d} x \mathrm{~d} y
\end{aligned}
$$

Since, in the case presented here, the centroid of the piston lies on the central axis, there are no moments due to the effect of gudgeon pin or centre of gravity offset. Hence, $M_{\mathrm{s}}=0$.

The instantaneous film shape $h_{i, j}$ is a combination of the initial nominal clearance $c$, the instantaneous deflection of the skirt $\delta_{i, j}$, the thermally distorted profile and the instantaneous location of the skirt relative to the cylinder liner at the top and its bottom edges (i.e. $e_{\mathrm{t}}$ and $\left.e_{\mathrm{b}}\right)$. For the case of the thrust side, the relationship takes the form: 
$h_{i, j}=S_{\mathrm{s}(i, j)}+d_{i, j}+c$

where $S_{\mathrm{s}(i, j)}$ is the combination of the thermally expanded profile and the overall skirt deflection. Particular attention has to be paid to the variable $d_{i, j}$, which amalgamates the effects of the instantaneous clearances $e_{\mathrm{t}}$ and $e_{\mathrm{b}}$ with the circumferential location on the skirt (for this given array size, the nodal separation $\Delta \varphi$ is $0.0208 \mathrm{rad}$ ):

$d_{i, j}=\Delta e_{\mathrm{t}}-(i-1)\left(\frac{\Delta e_{\mathrm{t}}-\Delta e_{\mathrm{b}}}{n x x-1}\right) \cos \left[\left(\frac{n y y+1}{2}\right) \Delta \varphi\right]$

where $\Delta e_{\mathrm{t}}=c-e_{\mathrm{t}}$ and $\Delta e_{\mathrm{b}}=c-e_{\mathrm{b}}$.

For the case of the anti-thrust side, one must accommodate the distortion due to the reaction force $f_{\mathrm{r} 1}$ and modify the signs of the corresponding $\Delta e_{\mathrm{t}}$ and $\Delta e_{\mathrm{b}}$ values.

\subsection{Deformation Analysis}

The methodology used for the estimation of the piston's deflection is the same as that presented by Littlefair et al. [19]. However, for completeness, a brief summary is provided here. The overall deflection on the piston skirt is due to four main factors. These are: (1) mechanical distortion due to forces acting orthogonal to the skirt surface, (2) distortion due to the application of combustion pressure on the piston crown surface, (3) thermal distortion due to the temperature gradient and (4) inertial-induced piston distortion due to the primary accelerative motion.

The normal reaction forces on the thrust and anti-thrust sides induce a mechanical distortion on the piston skirt. The formulation uses finite element analysis (FEA) for axisymmetric half-piston model, generated within the Patran environment. The mesh grid size in the model is $27 \times 47$ ( $n x x$ and nyy, respectively), having a nodal spacing of $1 \mathrm{~mm}$ on the skirt's surface (Fig. 5). The same mesh, including its positioning, is then used in the solution

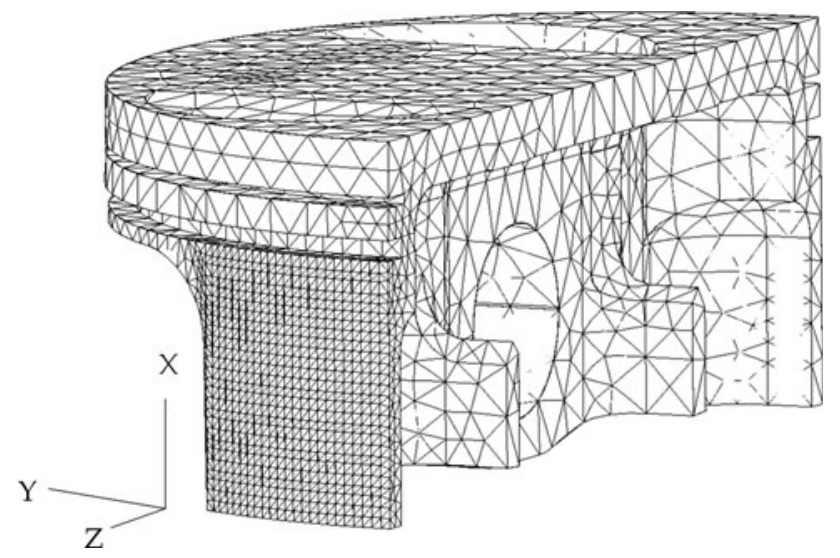

Fig. 5 The piston FEA model and mesh construction of Reynolds' equation, allowing for a direct implementation of the deflection values obtained.

The stiffness matrix is exported from the finite element analysis, and the preconditioned conjugate gradient (PCG) method (Dias Da Cunha and Hopkins [7]) is used to obtain the skirt's mechanical distortion $\left(\delta^{s}\right)$ as:

$$
\left[\delta^{\mathrm{s}}\right]=[K]^{-1}[F]
$$

where $[F]$ is the full force array including the forces acting at the skirt surface and $[K]$ is the complete body stiffness matrix.

Given the highly iterative nature of the transient analysis, a compliance matrix, $[A]$, is created to reduce the computational time burden for the solution of Eq. (18).

A single unit load $L_{\mathrm{u}}$ is applied orthogonal to the skirt surface at each nodal position, and the corresponding deflection is recorded for the y- and z-directions for all of the surface nodes. By repeating this process for each node location, in isolation and sequentially, a five-dimensional reduced array is formed: $A(i, j, k, l, n)$, where $i$ and $j$ refer to the applied load location, $k$ and $l$ denote the skirt nodal deflection position, and $n$ is either 1 or 2 for the y- or z-direction in which the deflection occurs.

Given the linear nature of the analysis, a scaled addition for each response shape due to a given load type can be performed. The summation of these effects is given by:

$\left[\delta_{n}^{\mathrm{s}}\right]_{k, l}=\sum_{i=1}^{n x x} \sum_{j=1}^{n y y} \sum_{k=1}^{n x x} \sum_{l=1}^{n y y}\left[\delta_{n}^{\mathrm{s}}\right]_{k, l}+\left([A]_{i, j, k, l, n} \cdot \frac{F_{(i, j)}}{L_{\mathrm{u}}}\right)$

where

$F_{i, j}=p_{(i, j)} \mathrm{d} x \mathrm{~d} y$

Using the same FEA model, the distortion due to combustion pressure can also be approximated. This is achieved by applying a single static case for a half-piston model with symmetrical boundary conditions. The constraining reaction is provided by the pin-bore axis with its $X Y Z$ directions constrained, replicating a stable vertical reaction from the gudgeon pin-bore interface. Since a linear response is still retained, the direct proportionality between the in-cylinder pressure and the skirt deflection in the $y-z$ plane is obtained.

A fast calculation procedure can be achieved by using a scaled solution. To obtain this scaling factor, three different combustion pressures $(2,5$ and $8 \mathrm{MPa})$ are applied on the piston crown. The shape of the distorted body, $\varepsilon$, is retained for both loading cases, but with different deflection values; the pair of simulations confirm a linear response $(\varepsilon)$. Thus, the overall distortion due to crown loading $\left(\delta^{c}\right)$ can be approximated by a scaled solution as:

$\left[\delta^{\mathrm{c}}\right]=\frac{p}{p_{\text {ref }}}[\varepsilon]$ 
This response is, however, subjected to a few assumptions:

- There is no gudgeon pin offset, and the cylinder pressure acts evenly on the piston crown. This is the configuration for the engine under investigation.

- The crown deflection has negligible effect on the direction of the application of pressure. At the maximum combustion pressure of $90 \mathrm{bar}$, the sense of application of pressure (surface normal) alters by a mere 0.1 degrees, which is quite insignificant. Therefore, the very small deflection of the piston crown at its edges does not set up an additional moment about the gudgeon pin.

- The vertical component of the constraint on the gudgeon axis acts to oppose the application of pressure (i.e. transfers the force through the connecting rod). Therefore, any horizontal component generated by the connecting rod angle is opposed by the interaction between the liner and the piston skirt. This is insignificant in changing the application of the gudgeon pin constraint.

Using a very similar approach, the piston's distortion due to the primary inertial effects can be evaluated. A set of acceleration values are fed into the same finite element model, applied to the overall piston structure. A shape array $\varepsilon_{\text {ip }}$ or $\varepsilon_{\text {in }}$ is obtained depending on the sense of motion of the piston within the engine cycle (up- or down-stroke). The deflection $\delta^{\text {in }}$ is, then, given as:

$\left[\delta^{\text {in }}\right]=\frac{\ddot{x}}{\ddot{x}_{\text {ref }}}\left[\varepsilon_{\text {ip }}\right] \quad$ or $\quad\left[\delta^{\text {in }}\right]=\frac{\ddot{x}}{\ddot{x}_{\text {ref }}}\left[\varepsilon_{\text {in }}\right]$

Finally, the effect of thermal distortion can be established. A 3D temperature distribution has been obtained on a spark-ignition engine of a similar power output running at wide open throttle conditions [3]. Using these as the target temperatures and altering the convective coefficients accordingly within a Nastran thermal solution, a $3 \mathrm{D}$ temperature profile is created. This enables a finite element analysis to obtain the thermal expansion of the piston relative to the uniform base geometry at ambient temperature. This single thermally expanded profile is used as the base piston skirt profile, $s_{i, j}$ to produce the overall expression for the nodal deflection [used in Eq. (16)]:

$S_{\mathrm{s}(i, j)}=s_{i, j}+\delta_{i, j}^{\mathrm{s}}+\delta_{i, j}^{\mathrm{c}}+\delta_{i, j}^{\mathrm{in}}$

\subsection{Method of Solution}

The solution methodology is intrinsically iterative, accounting for a full numerical solution of Reynolds equation and a step-by-step numerical integration of equations of motion. The integration algorithm chosen is the linear acceleration method proposed by Timoshenko et al. [39], for the solution of nonlinear dynamic problems involving vibration-induced impact and/or friction. It is based on Newmark's algorithm [25], and previous experience has shown the effectiveness and accuracy of this method for contact dynamics problem (Rahnejat [32] and De la Cruz et al. [6]).

After some manipulation, the non-dimensional form of Reynolds' equation (10) can be defined as (non-dimensional parameters are provided in "Appendix 2"):

$$
\begin{aligned}
& \frac{\partial}{\partial X}\left(\frac{\bar{\rho} H^{3}}{\bar{\eta}} \frac{\partial P}{\partial X}\right)_{i, j}+k^{2} \frac{\partial}{\partial Y}\left(\frac{\bar{\rho} H^{3}}{\bar{\eta}} \frac{\partial P}{\partial Y}\right)_{i, j} \\
& \quad=\psi\left\{\left(\frac{\partial(\bar{\rho} H U)}{\partial X}\right)_{i, j}+\frac{R_{\mathrm{x}}}{b} S^{*}\right\}
\end{aligned}
$$

where $\psi=12 \frac{u \eta_{\mathrm{o}} R_{x}^{2}}{P_{\mathrm{h}} b^{3}} ; \quad S^{*}=\frac{\partial h / \partial t}{u}$ and $k=\frac{b}{a}$

The term $\partial h / \partial t$ is the squeeze film velocity, which represents the history of film thickness variation with time during the simulation study. Therefore, instantaneous changes in contact kinematics and film thickness variation with time are retained in the tribological study. The inclusion of this term in Reynolds equation yields a transient analysis. When this is not retained as in some numerical analyses, a steady-state or quasi-static equilibrium in the conjunction is implied (i.e. the applied side force equates the contact reaction within a specified limit).

Equation (24) is then solved using the low relaxation effective influence Newton-Raphson (EIN) method with Gauss-Seidel iterations [15].

The overall algorithm describing the full solution can be summarised in the following four steps:

Step 1 Pressure $p$ and displacements $e_{\mathrm{t}}$ and $e_{\mathrm{b}}$ are used to determine the deflections with the aid of the compliance matrix. The initial film shapes for thrust and anti-thrust sides are thus obtained.

Step 2 The film shapes are fed into the Reynolds' solver, through an internal iterative procedure, relaxing the pressures as:

$p_{(i, j)}^{q}=p_{(i, j)}^{q-1}+\Omega_{p} \Delta p_{(i, j)}^{q}$

The following convergence criterion is met through an iterative process:

$\frac{\sum_{i=1}^{27} \sum_{j=1}^{47}\left|p_{(i, j)}^{q}-p_{(i, j)}^{q-1}\right|}{\sum_{i=1}^{27} \sum_{j=1}^{47} p_{(i, j)}^{q}} \leq \varepsilon_{p}$

If this criterion is not met, the new pressures are again used to determine deflections, retaining the values of $e_{\mathrm{t}}$ and $e_{\mathrm{b}}$.

Step 3 Once a converged pressure distribution is achieved, the hydrodynamic reaction loads $f_{\mathrm{r} 1}$ and $f_{\mathrm{r} 2}$ and 
the corresponding moments $m_{\mathrm{fr} 1}$ and $m_{\mathrm{fr} 2}$, acting on the piston skirt sides, are calculated.

It is important to note that given the transient nature of the problem, the standard load convergence usually found in quasi-static analyses is replaced by dynamic convergence of equations of motion based on acceleration. This takes into account inertial forces instantaneously applied to the piston and is the essence of a transient dynamic analysis [12].

Step 4 The loads and moments calculated in Step 3 are fed into the linear acceleration method. These induce changes in the system state, resulting in varying accelerative motions. Therefore, a dynamic convergence has to be achieved for a set of pressures, loads, moments and deflections. The dynamic convergence criteria are [32]:

$$
\begin{gathered}
\left|\frac{\left.\ddot{e}_{\mathrm{t}}\right]_{p}^{q}-\left[\ddot{e}_{\mathrm{t}}\right]_{p}^{q-1}}{\left[\ddot{e}_{\mathrm{t}}\right]_{p}^{q}}\right| \leq 1 \times 10^{-4} \text { and } \\
\left|\frac{\left.\ddot{e}_{\mathrm{b}}\right]_{p}^{q}-\left[\ddot{e}_{\mathrm{b}}\right]_{p}^{q-1}}{\left[\ddot{e}_{\mathrm{b}}\right]_{p}^{q}}\right| \leq 1 \times 10^{-4}
\end{gathered}
$$

Following this step, the integrator provides updated values for $e_{\mathrm{t}}$ and $e_{\mathrm{b}}$. If the criteria in Eq. (27) are satisfied, then the integrator updates the time step (a crank angle advance) and the procedure returns to step 1 .

An in-house piece of software was developed for this methodology in Fortran 95 (Linux environment), using the Intel ifort compiler, NAG libraries and OpenMP for parallel programming. The processor was a $2.9 \mathrm{GHz}$ dual intel Xeon quad core chip. For a typical time step of $5 \mu$ s, at the nominal engine speed of 4,250 rpm and full throttle conditions, the computation time for one full engine cycle is around $8 \mathrm{~h}$.

\section{Results and Discussion}

The Honda CRF $450 \mathrm{R}$ engine was run for a number of speed/load combinations. The results for two specific conditions are reported here. These are at the engine speeds of 4,250 and 6,250 rpm, both with wide open throttle. Note that this is a relatively short stroke race engine, which idles smoothly at 4,000 rpm. Thus, the speed of 4,250 rpm represents a relatively low speed application. This together with high load (wide open throttle) represents relatively poor lubrication condition (low speed, high load). The higher speed of $6,250 \mathrm{rpm}$ represents medium speed in highway driving.

The thermocouples installed on the liner (Sect. 2) show an average temperature of around $110{ }^{\circ} \mathrm{C}$, once steadystate conditions are reached. Therefore, the temperature of entrant lubricant into the contact is assumed to remain the same.
Figure 6 presents the variation in in-cylinder pressure and crankshaft rotational velocity as measured on the engine test bed for one full engine cycle. The cases depicted constitute the input parameters necessary to run the numerical model. Large fluctuations in the instantaneous rotational velocity are inherent in single-cylinder engines with relatively low rotational inertia [4]. This is a key feature of the dynamic model, where the instantaneous (rather than the averaged/nominal) engine speed is used to calculate the primary piston kinematics [Eqs. (6), (7) and (8)]. This is a realistic approach, not often noted in analysis of single-cylinder engines in literature.

The in-cylinder pressure is measured using a Kistler spark-plug-type pressure transducer, inserted into the combustion chamber. This enables calculation of the gas force $f_{\mathrm{g}}$ acting on the piston crown surface. Since there is no gudgeon pin offset, $C_{\mathrm{pb}}$ in this engine configuration, the gas force is assumed to be evenly distributed over the piston crown.

All the numerical results presented here correspond to an overall simulation run of $1,440^{\circ}$ crank angle (i.e. two full engine cycles: Honda CRF $450 \mathrm{R}$ is a 4-stroke naturally aspirated engine). The reason behind this is to ascertain that any transient period of the numerical integrator has elapsed and a steady-state response has been reached. For plotting purposes, only the second cycle is presented, always starting from a crankshaft angle of $-180^{\circ}$, corresponding to the beginning of the compression stroke. This is then followed by the power, exhaust and intake stokes, ending up at the crank angle of $540^{\circ}$.

Given the transient nature of the results obtained, it is worth starting the analysis with a description of the piston's secondary motion. For all the cases shown, the piston's minimum nominal clearance, $c$, with the liner subjected to uniform thermally distorted conditions is $18 \mu \mathrm{m}$. In reality, thermal distortion of the liner varies along its axial direction because of the axial temperature distribution. Additionally, the cylinder blocks; thus, the bore/liner undergoes dynamic thermo-elastic deformation, which is not taken into account in the current analysis. The dynamic block thermal distortion is found to be insignificant for the current short interval of testing, but can become important in many engines as reported by Piao and Gulwadi [29]. This means that when the piston is perfectly aligned, the starting $e_{\mathrm{t}}$ and $e_{\mathrm{b}}$ values are 39 and $60 \mu \mathrm{m}$, respectively.

Figures 7 and 8 show the $e_{\mathrm{t}}$ and $e_{\mathrm{b}}$ responses for the four strokes undergone by the piston. It must be noted that these two parameters are used in the dynamic analysis to describe the rigid body motions of the piston. This means that $e_{\mathrm{b}}$, for instance, can travel $120 \mu \mathrm{m}$ and still be within the confine of the piston-liner clearance. However, given that the skirt is quite flexible, $e_{\mathrm{b}}$ value can exceed the stated limit due to thermo-elastic deformation, reaching 
Fig. 6 Combustion pressure and engine speed variation

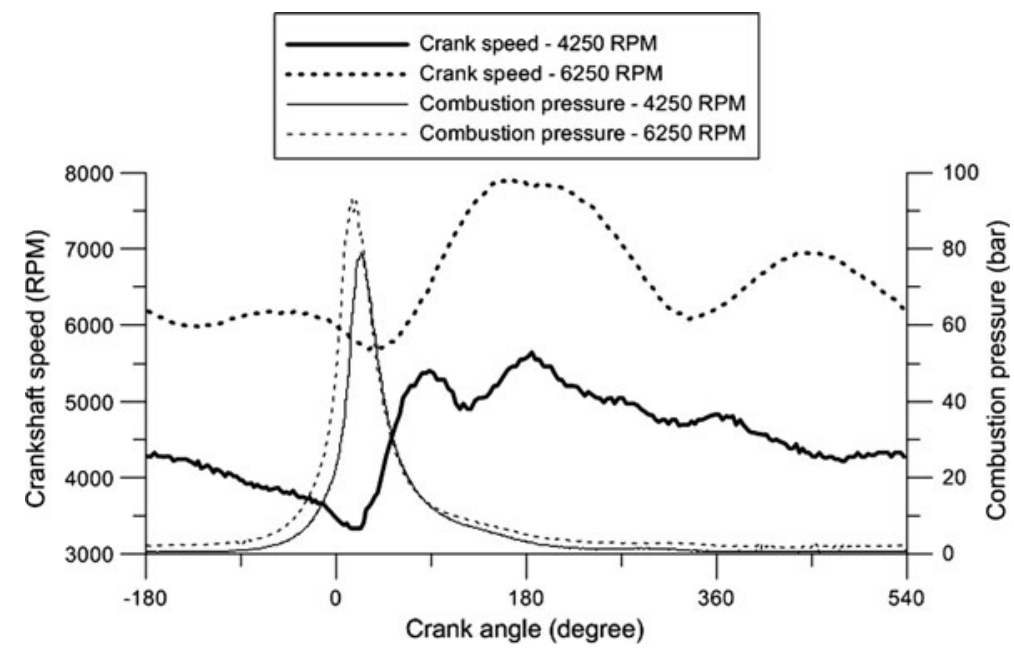

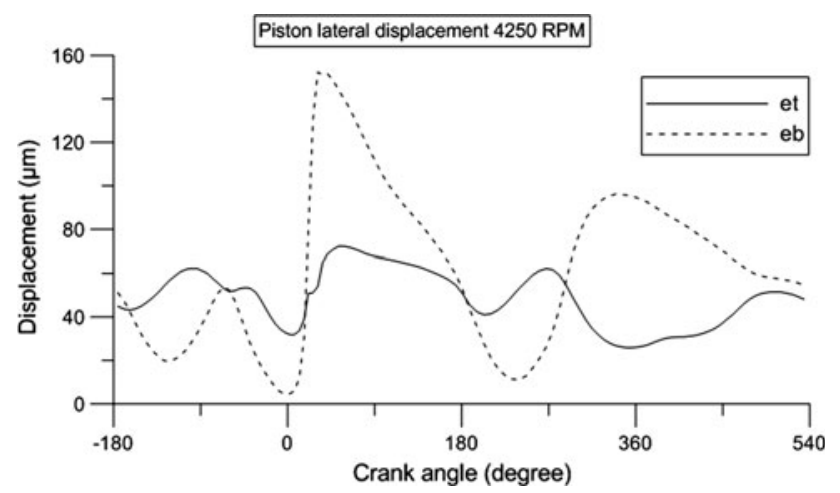

Fig. 7 Piston lateral motion (displacement) for 4,250 rpm

displacements of up to $152 \mu \mathrm{m}$ in the case of the engine speed of 4,250 rpm. This difference of $30 \mu \mathrm{m}$ implies that at that specific crank angle (highest side load on the thrust side), a large deflection would be expected. Similarly, for the case of the higher engine speed of 6,250 rpm, not only $e_{\mathrm{b}}$ reaches its maximum excursion of $150 \mu \mathrm{m}$, but also a minimum of $-23 \mu \mathrm{m}$. The negative sign indicates that a large deflection takes place on the anti-thrust side.

Interestingly, $e_{\mathrm{t}}$ undergoes a much smoother motion compared to $e_{\mathrm{b}}$. The overall displacement variation along the full cycle is around $43 \mu \mathrm{m}$, as opposed to the $175 \mu \mathrm{m}$ encountered in the $6,250 \mathrm{rpm}$ case. The large changes in displacement observed at $e_{\mathrm{t}}$ at both investigated speed cases are as the result of the relatively low stiffness observed towards the bottom of the skirt (preferentially compliant skirt design). The purpose of this is twofold. It dampens the secondary motion, absorbing a portion of the kinetic energy. It also ensures in the downward sense of the piston the inlet wedge effect by altering the inlet geometry (radius). This enhances the thermo-elastic deformation at the bottom of the skirt because of a lower structural stiffness there. This is important during the higher mechanical

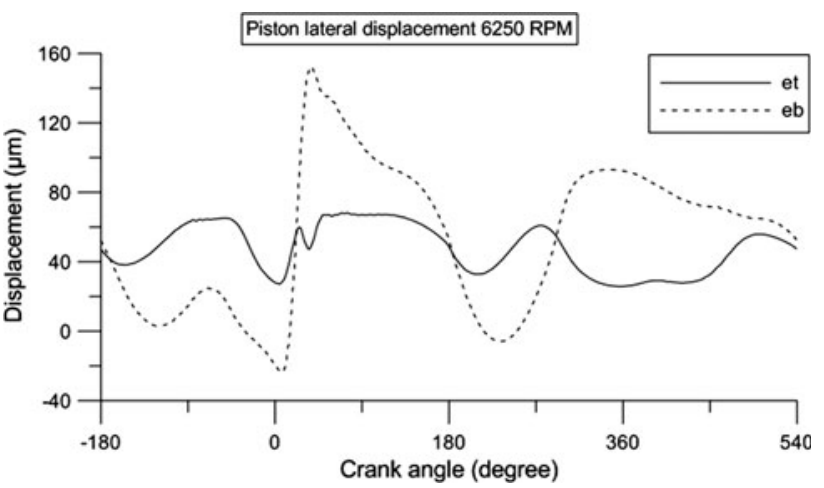

Fig. 8 Piston lateral motion (displacement) for 6,250 rpm

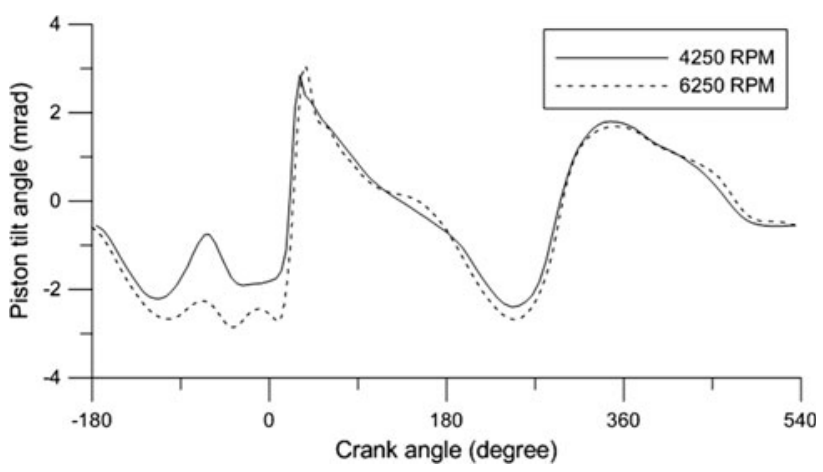

Fig. 9 Piston tilt angle

and thermal loading in the combustion stroke. Higher stiffness at the top of the piston skirt provides the necessary load-carrying capacity. The effect of ensuring a suitable inlet wedge enhances lubricant entrainment into the contact and thus improves the mechanism of lubrication. This observation seems to be in line with the main design characteristics for this high-performance engine, a phenomenon also reported by Bai [1]. 

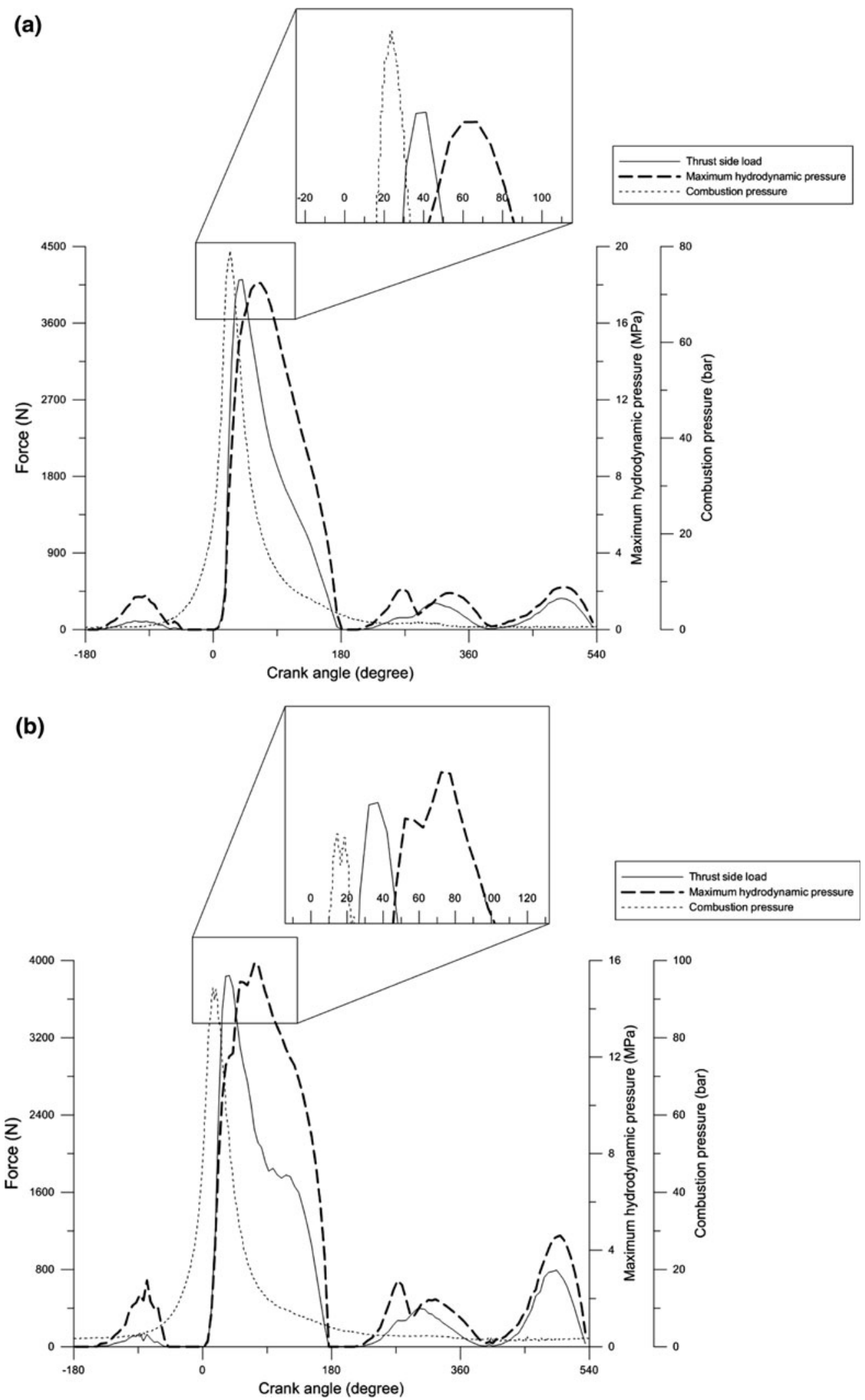

Fig. 10 Combustion pressure, thrust side load and maximum generated hydrodynamic pressure for: a 4,250 rpm and b 6,250 rpm 
Once $e_{\mathrm{t}}$ and $e_{\mathrm{b}}$ are known, the piston tilt angle, $\beta$, can be approximated as:

$\beta=\tan ^{-1}\left(\frac{e_{\mathrm{b}}-e_{\mathrm{t}}}{L}\right)$

The reference positions for $e_{\mathrm{t}}$ and $e_{\mathrm{b}}$ are between the thermally deformed liner and the piston from their original starting positions when their axial alignments are set. In motion and with the combination of the various mechanical distortions, these values alter significantly. In some cases, where the distortions are significant enough, the values may become negative.

The results, after implementing the above relationship to the data contained in Figs. 7 and 8, are shown in Fig. 9. It can be observed that the highest engine speed induces a larger piston tilt in the compression stroke, whereas on the other three strokes both the simulated engine speeds produce very similar tilt angles. This implies that higher reaction loads occur in that vicinity. As it would be expected, piston tilt reduces significantly (almost

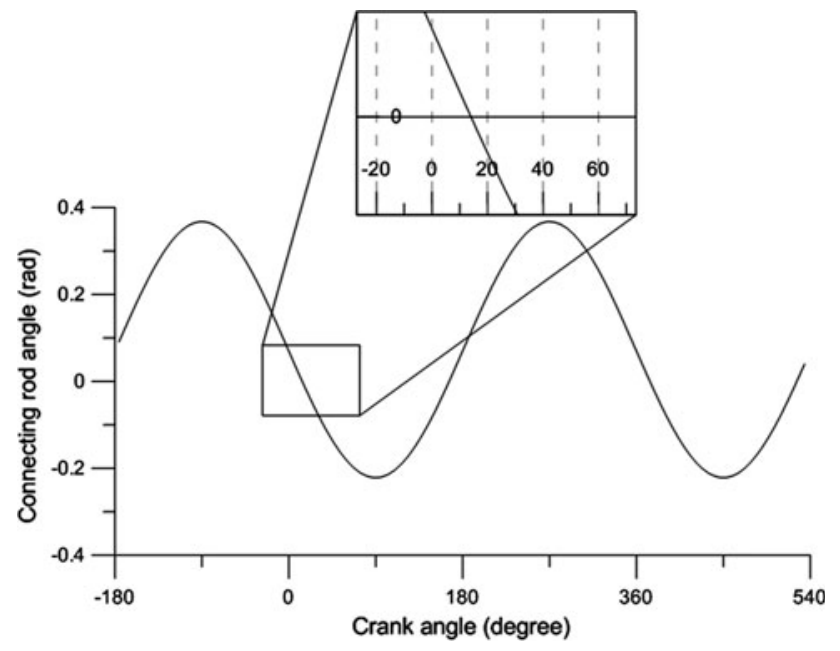

Fig. 11 Connecting rod angle variation for 4,250 and $6,250 \mathrm{rpm}$ diminishing) at the maximum combustion pressure. Again, this is a design characteristic of the engine used, where a 7.5-mm crankshaft offset ensures adherence of the piston to its thrust side.

The main forcing mechanism is the in-cylinder pressure. Its magnitude and peak value dictate the system dynamics. Figure 10 shows the phase difference between the combustion pressure, the generated thrust side load and the maximum generated hydrodynamic pressure on the thrust side. There is a consistent lag between the maximum peak values for these parameters: loads and pressures. Peak combustion pressure occurs at $23^{\circ}$ crank angle, whereas the maximum side load is not reached until $38^{\circ}$ crank angle and the generated hydrodynamic pressure peaks at $62^{\circ}$ (for the engine speed of 4,250 rpm). Similarly, for the $6,250 \mathrm{rpm}$, the peak combustion pressure occurs at $15^{\circ}$, maximum load at $33^{\circ}$ and maximum hydrodynamic pressure at $75^{\circ}$. An important point to note is that often reported analyses assume that the worst loading conditions occur at the maximum combustion pressure. As shown here, secondary piston inertial dynamics contribute to altering this presumption. It should be noted that these characteristics are often confined to single-cylinder geometries with low rotational inertia, which are inherently unbalanced and endure large in-cycle speed variations. The addition of a crank offset acts to increase the torque around the location of maximum combustion pressures which, as a result, reduce the magnitude of the side load acting upon the skirt.

The presented results include a crankshaft offset of $7.5 \mathrm{~mm}$, emulating the running conditions of the singlecylinder engine studied. Altering this value would not only shift the location of maximum side load but also significantly increase its magnitude, inherently affecting the maximum hydrodynamic pressure. Figure 11 presents the variation in connecting rod angle with respect to crank angle position for the 4,250 and 6,250 rpm cases. Given that the motion of the connecting rod is geometrically
Fig. 12 Force analysis for 4,250 rpm

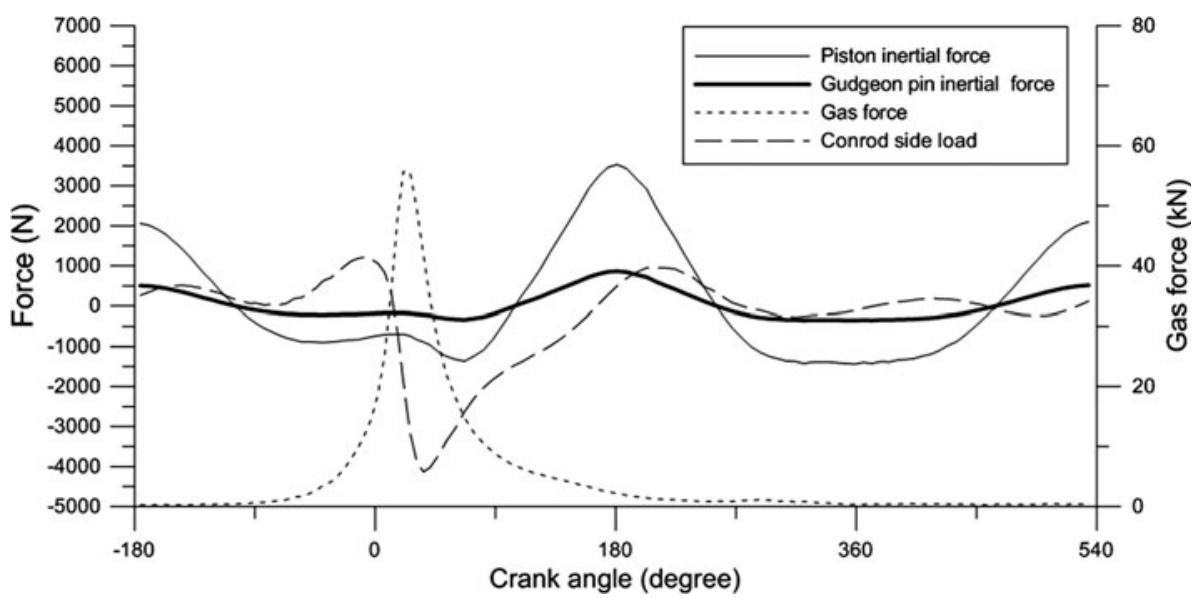


Fig. 13 Force analysis for $6,250 \mathrm{rpm}$

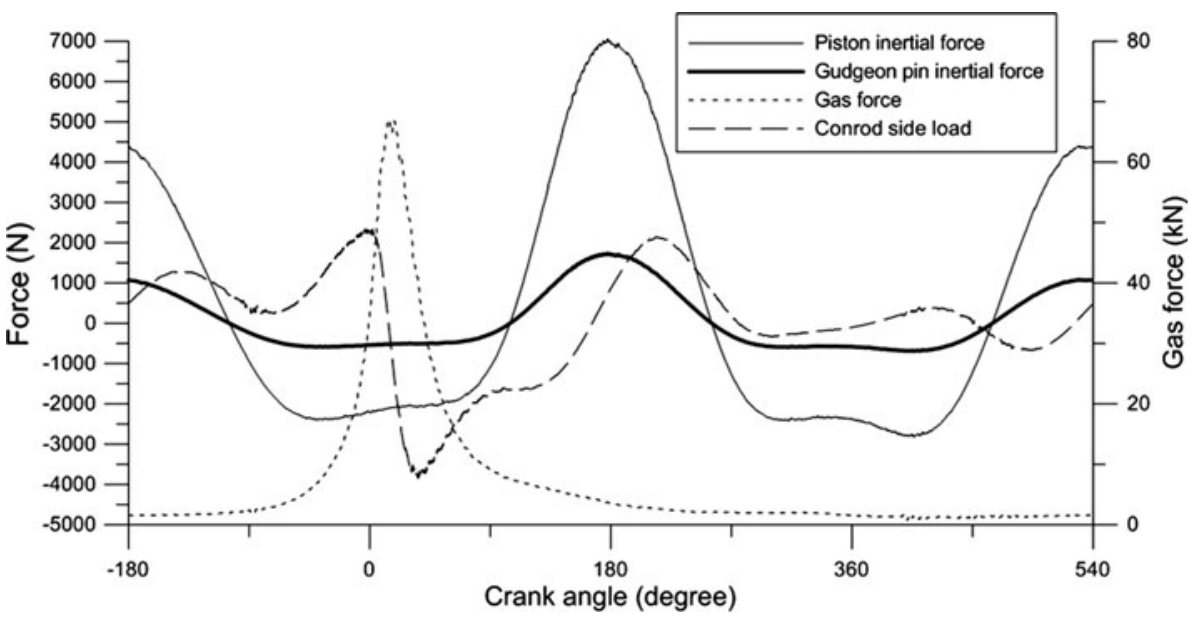

(plotted on the same axes in Figs. 12,13) shows that higher values of $f_{\mathrm{s}}$ occur between $90^{\circ}$ and $180^{\circ}$ crank angles and are purely due to inertial effects, thus a function of the engine speed. This is an important characteristic because of the inherent higher hydrodynamic pressures generated in this region.

With the system dynamics thoroughly examined, it is important to focus on the instantaneous conjunctional behaviour of the piston skirt-cylinder liner. Snapshots of film thickness profile and pressure distribution are presented for the locations of maximum combustion pressure, maximum side load and maximum hydrodynamic contact pressures (Fig. 14 for the 4,250 rpm; Fig. 15 for the $6,250 \mathrm{rpm})$. These Figures are of particular interest because they show a large amount of data in a very condensed manner. Even though they essentially show the conditions at a particular crank angle location, by observing them sequentially, the effect of piston tilt can be appreciated. In both cases, the piston is almost perfectly aligned (Fig. 9) at the location of maximum combustion pressure (note that the top end, $e_{\mathrm{t}}$, has a smaller clearance than the bottom end, $e_{\mathrm{b}}$ ). Note that in Figs. 14 and 15, the piston crown is located at $27 \mathrm{~mm}$ in the axial direction. As the cycle progresses, it can be seen that $e_{\mathrm{b}}$ reduces, not only showing a rigid tilt, but it is also as a result of significant skirt deformation. The contact footprint variation can be visualised clearly in Fig. 16, where the oil film thickness contours and the corresponding pressure isobars are shown for the maximum load case at 6,250 rpm. The minimum film thickness in Fig. 16a is shown by the $2-\mu \mathrm{m}$ contour region. This film thickness is five times larger than the composite root mean square surface roughness of the contacting surfaces, at $0.4 \mu \mathrm{m}$ (with a surface roughness of the liner being that of $0.26 \mu \mathrm{m} R_{\mathrm{a}}$ and that of the piston skirt being $0.3 \mu \mathrm{m} R_{\mathrm{a}}$ ). Therefore, no boundary or mixed regime of lubrication would be expected for the engine testing conditions reported. It should be noted that the test piston was specifically manufactured for this study, with 

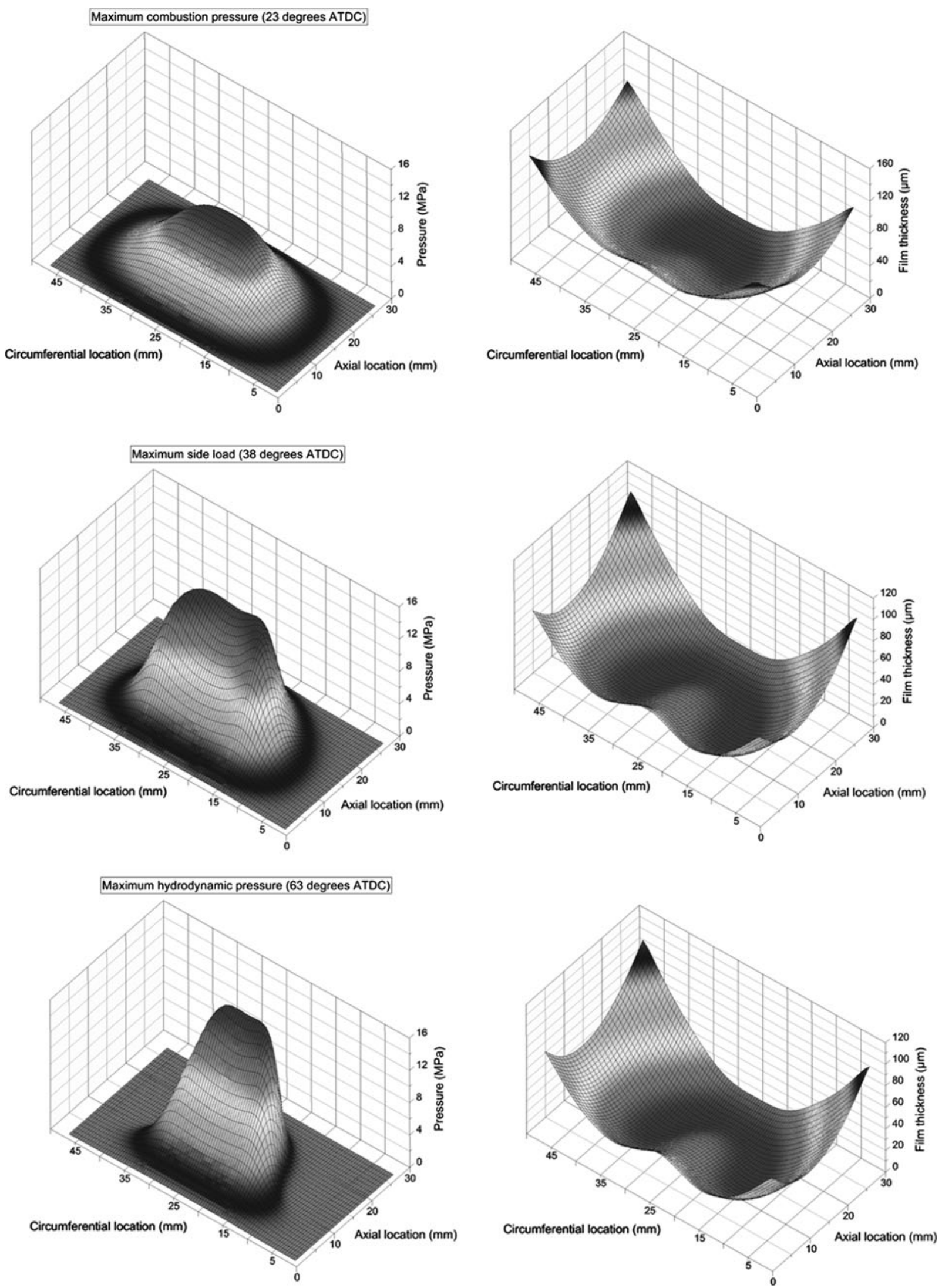

Fig. 14 Film profiles and pressure distributions for 4,250 rpm 

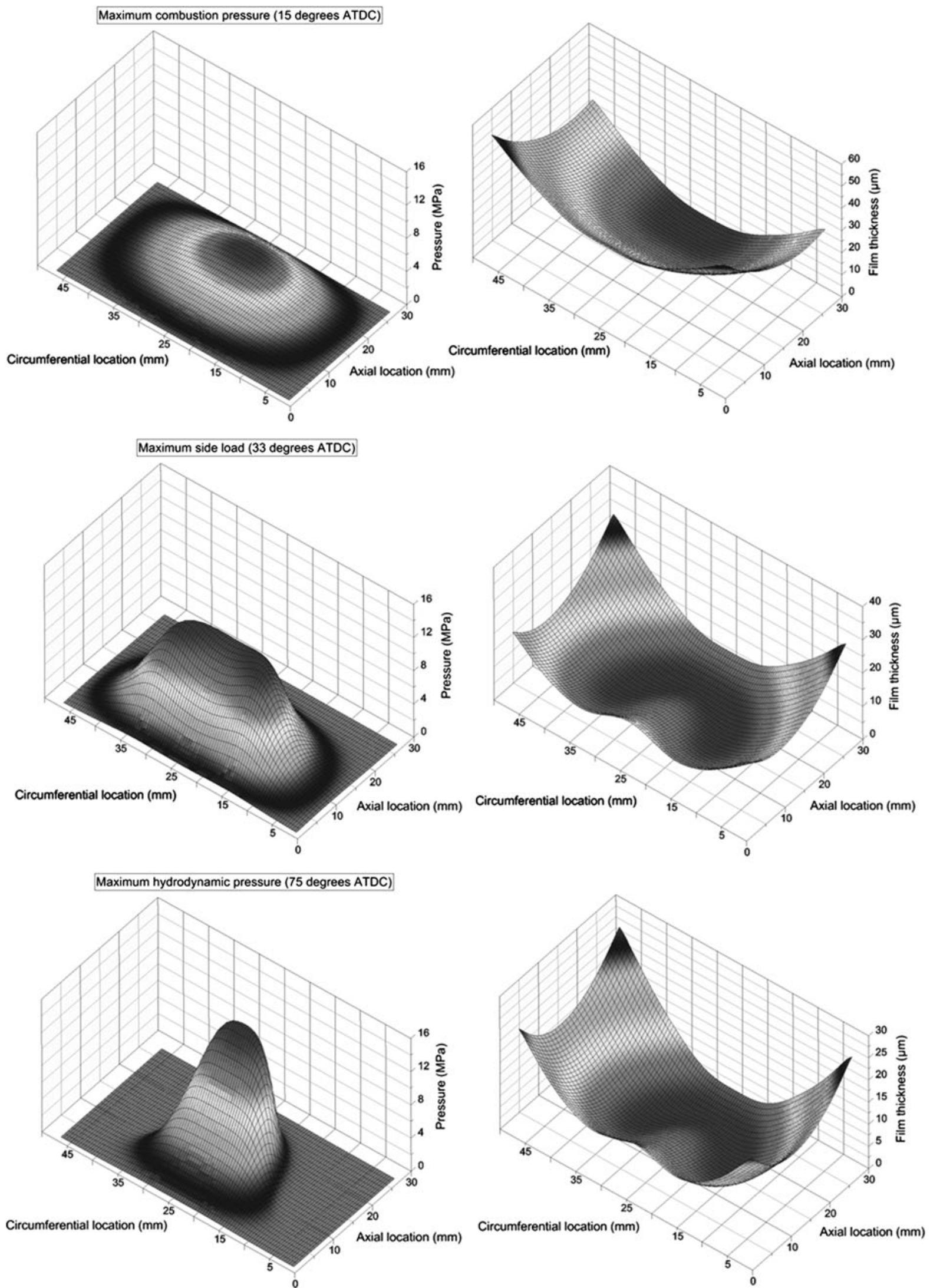

Fig. 15 Film shape and pressure distributions for $6,250 \mathrm{rpm}$ 

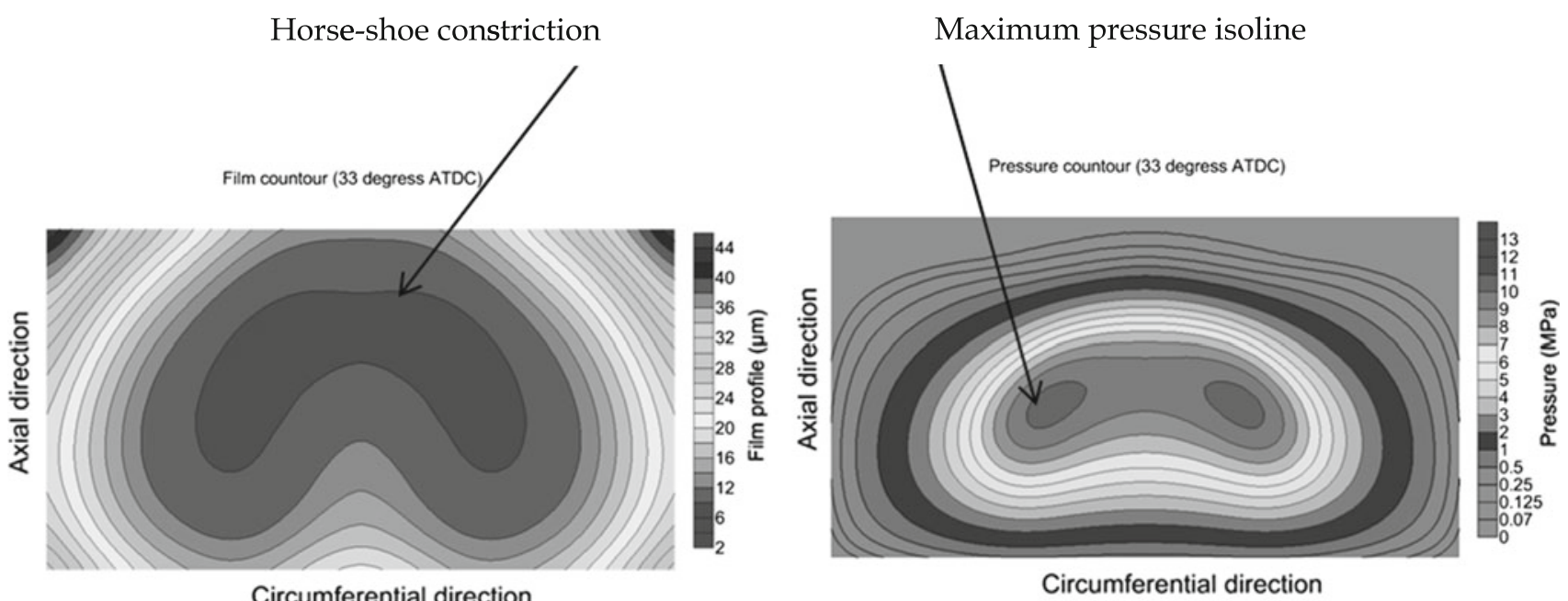

Fig. 16 Contour of film profile and pressure distribution for maximum side load (33 $)$ at $6,250 \mathrm{rpm}$

super-finish topography to reduce any chance of solid boundary interactions and facilitate ultrasonic oil film measurement.

Referring back to Fig. 6, the highest measured combustion pressure is encountered at the engine speed of $6,250 \mathrm{rpm}$ at $92 \mathrm{bar}$ as opposed to $80 \mathrm{bar}$ for the engine speed of 4,250 rpm. One may, therefore, surmise that higher hydrodynamic pressures and side loads would ensue at the higher engine speeds. However, this is to the contrary, because of the crankshaft offset and the connecting rod angle seen at the position of maximum pressure. Even though the combustion peak is higher at $6,250 \mathrm{rpm}$, it actually occurs $8^{\circ}$ crank angle prior to that at $4,250 \mathrm{rpm}$ in the power stroke as the ignition point is advanced as both the load and speed increase. Therefore, the effect of a higher gas force on the side load is diminished by a more vertical connecting rod orientation at the higher engine speed. The other reason for lower generated hydrodynamic pressures at the higher engine speed is related to the effect of higher speeds of entraining motion (given the assumption of fully flooded conditions). Higher speeds lead to thicker lubricant films. This means that for a similar loading condition the peak hydrodynamic pressure is reduced at a higher engine speed in the case of this type of engine.

\section{Experimental Verification}

It is important to present experimental verification of numerical predictions. With the arrangement described in the experimental section and, again, using the engine speed of 4,250 rpm, direct comparisons between numerically predicted film thickness and shape with those experimentally measured are presented.
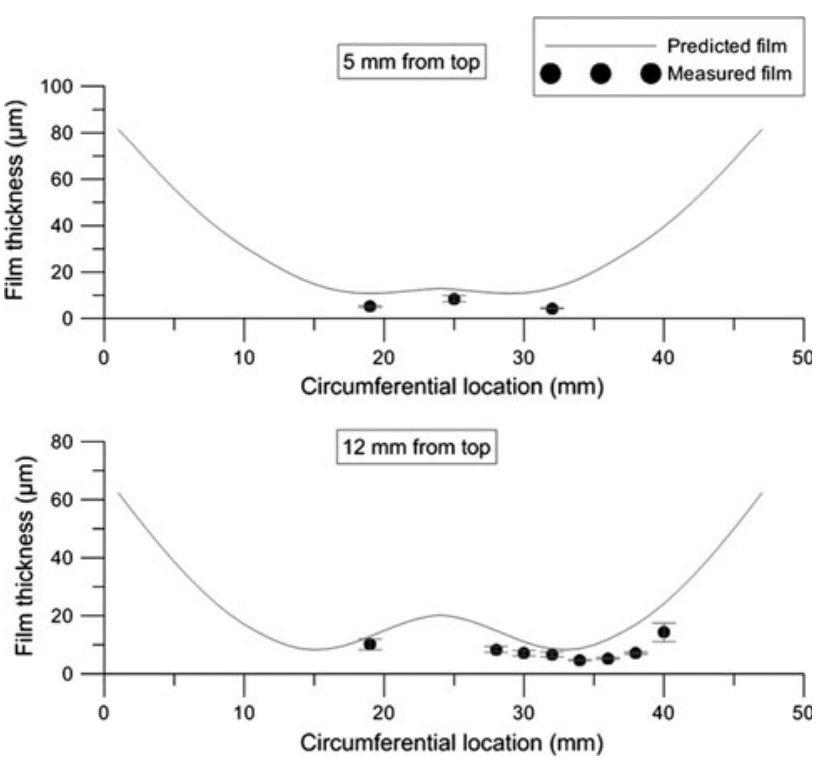

Fig. 17 Experimental and numerical comparison $\left(38^{\circ}\right.$ crank angle at $4,250 \mathrm{rpm})$

Due to the intrinsic difficulties of the experimental measurement of film thickness under transient conditions, the data available are not necessarily for the crankshaft locations presented above. After exhaustive data processing, it was found that the largest amount of data successfully collected was at $38^{\circ}, 43^{\circ}$ and $53^{\circ}$ crank angles. Therefore, validation work is conducted for these specific crank angle locations.

In the plots presented, not only the crank angle has to be noted, but also the location on the skirt relative to its top edge (piston crown). As depicted in Fig. 1, there are three rows and three or 12 columns (depending on the row) of ultrasonic sensors. In Fig. 17, the results are presented for $38^{\circ}(4,250 \mathrm{rpm})$ and for the rows of sensors at 5 and 

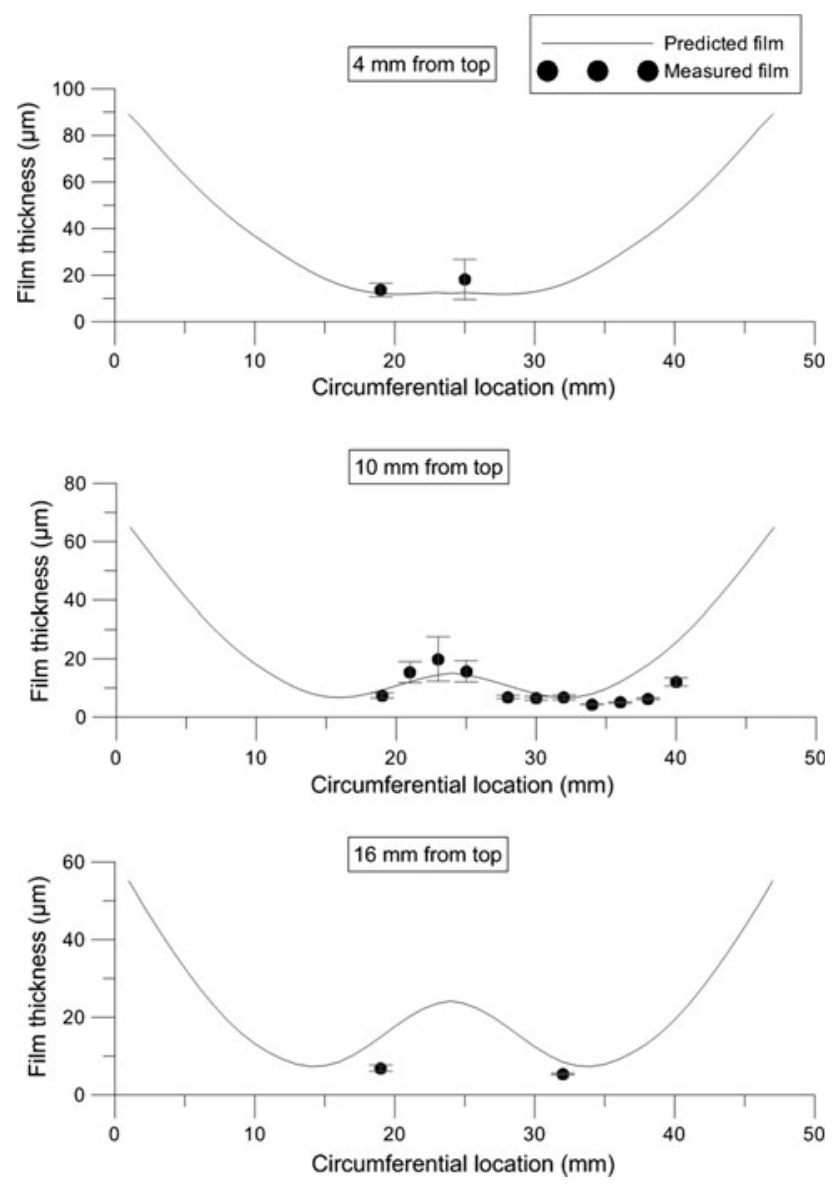

Fig. 18 Experimental and numerical comparison $\left(43^{\circ}\right.$ crank angle at $4,250 \mathrm{rpm})$

$12 \mathrm{~mm}$ from the top of the skirt. There are not always data captured for all the sensors along these rows. Error bars have also been marked, showing the standard deviation of the results for data obtained for 70 to 120 engine cycles. It can be appreciated that the results are, in general, accurate. Most importantly, the measured film thickness and shape are used for comparison with the predictions.

In a very similar manner, Fig. 18 shows the measured values at $43^{\circ}$ crank angle, for the rows at 4,10 and $16 \mathrm{~mm}$ from the top of the skirt. Again, a similar trend in terms of the overall shape of the skirt can be found for the predicted and experimental results. It seems that around the edges of the skirt (circumferential location $35 \mathrm{~mm}$ and higher in Figs. 17 and 18), the largest differences between the numerical predictions and experimental measurements are encountered. It is believed that this effect could be because of two reasons. Firstly, this anomaly may be related to the cylinder-out-ofroundness or mechanical distortion, two parameters that are not accounted for in the current analysis [31]. Secondly, an alternative suggestion may be that the thermal distortion of the piston and the liner would require an even more detailed model with enhanced operational boundary conditions.
Nevertheless, remarkably good agreement is evident between the predictions and measurements.

\section{Concluding Remarks}

A detailed methodology to predict piston skirt-liner conjunctional performance is presented, which includes the effect of all major causes contributing to the thermo-elastic deformation of the contiguous contacting solids under transient dynamic conditions. The elastohydrodynamics of the contact is also embedded within the transient dynamic analysis. The analysis shows that short piston skirts of light high-performance pistons with preferential skirt structural compliance promote good inlet wedge through most of the heavily loaded portion of the cycle. The predictions are verified by in situ non-invasive measurement of film thickness under transient conditions from a fired engine operating at various speed-load combinations. Further work will account for additional cylinder liner distortions and experimental techniques to acquire the skirt's instantaneous operating temperatures.

Acknowledgments The authors wish to express their gratitude to the EPSRC for the financial support extended to the Encyclopaedic Program Grant, under which this research was carried out. Thanks are also due to the consortium of industrial partners of the Encyclopaedic project, particularly in this instance Capricorn Automotive.

Open Access This article is distributed under the terms of the Creative Commons Attribution License which permits any use, distribution, and reproduction in any medium, provided the original author(s) and the source are credited.

\section{Appendix 1: Sine and Cosine Harmonics Used in the Derivation of the Piston's Primary Motion Kinematics}

$$
\begin{aligned}
\Lambda= & \frac{r_{\mathrm{p}}}{L} \\
\Xi= & \frac{C_{\mathrm{p}}}{r_{\mathrm{p}}} \\
A_{0}= & \sqrt{(1+1 / \Lambda)^{2}}-\Xi^{2}-\frac{1}{\Lambda}+\left(\frac{1}{4} \Lambda+\frac{3}{64} \Lambda^{3}+\frac{5}{256} \Lambda^{5}\right)+ \\
& +\frac{1}{2}(\Lambda \Xi)^{2}\left(\frac{1}{\Lambda}+\frac{3}{4} \Lambda+\frac{45}{64} \Lambda^{3}\right)+\frac{1}{8}(\Lambda \Xi)^{4}\left(\frac{1}{\Lambda}+\frac{15}{4} \Lambda\right) \\
A_{1}= & -1 \\
A_{2}= & -\left(\frac{1}{4} \Lambda+\frac{1}{16} \Lambda^{3}+\frac{15}{512} \Lambda^{5}\right)+\frac{3}{8} \Lambda^{3} \Xi^{2}\left(1+\frac{5}{4} \Lambda^{2}\right) \\
& +\frac{15}{32} \Lambda^{5} \Xi^{4}
\end{aligned}
$$




$$
\begin{aligned}
B_{1}= & -\left[(\Lambda \Xi)\left(1+\frac{3}{8} \Lambda^{2}+\frac{15}{64} \Lambda^{4}\right)+\frac{1}{2}(\Lambda \Xi)^{3}\left(1+\frac{15}{8} \Lambda^{2}\right)\right. \\
& \left.+\frac{3}{8}(\Lambda \Xi)^{3}\right] \\
B_{3}= & \frac{1}{8} \Lambda^{3} \Xi\left(1+\frac{15}{16} \Lambda^{2}\right)+\frac{5}{16} \Lambda^{5} \Xi^{3}
\end{aligned}
$$

\section{Appendix 2: Non-dimensional Parameters in Reynolds' Equation}

$$
\begin{aligned}
& X=x / b \\
& Y=y / a \\
& \bar{\rho}=\rho / \rho_{0} \\
& \bar{\eta}=\eta / \eta_{0} \\
& H=h R_{\mathrm{x}} / b^{2} \\
& P=p / P_{\mathrm{h}} \\
& \bar{t}=u t / R_{\mathrm{x}} \\
& U=u / u_{\mathrm{av}} \\
& W^{*}=W /\left(E^{\prime} R_{\mathrm{x}} L\right) \\
& G^{*}=\alpha E^{\prime}
\end{aligned}
$$

\section{References}

1. Bai, D.: Modelling Piston Skirt Lubrication in Internal Combustion Engines. PhD Thesis, Massachusetts Institute of Technology, USA, 2012

2. Balakrishnan, S., Rahnejat, H.: Isothermal transient analysis of piston skirt-to-cylinder wall contacts under combined axial, lateral and tilting motion. J. Phys. D Appl. Phys. 38, 787-799 (2005)

3. Bosch: Automotive Handbook, 7th edn, John Wiley and Sons (2007)

4. Boysal, A., Rahnejat, H.: Torsional vibration analysis of a multibody single cylinder internal combustion engine model. Appl. Math. Model. 21(8), 481-493 (1997)

5. D'Agostino, V., Guida, D., Ruggiero, A., Russo, C.: Optimised EHL piston dynamics computer code. In: AITC-AIT, International Conference on Tribology, 20-22 Sept 2006, Parma, Italy

6. De la Cruz, M., Chong, W.W.F., Teodorescu, M., Theodossiades, S., Rahnejat, H.: Transient mixed thermo-elastohydrodynamic lubrication in multi-speed transmissions. Trib. Int. 49, 17-29 (2012)

7. Dias Da Cunha, R., Hopkins, T.: PIM 1.1-The Parallel Iterative Method Package for Systems of Linear Equations User's GuideFortran 77 Version Technical Report Computing Laboratory. University of Kent at Canterbury, Kent (1994)

8. Dowson, D., Higginson, G.R.: A numerical solution to the elastohydrodynamic problem. J. Mech. Eng. Sci. 1(1), 6-15 (1959)

9. Dwyer-Joyce, R., Green, D., Balakrishnan, S., Harper, P., Lewis, R., Howell-Smith, S., King, P., Rahnejat, H.: The Measurement of Liner-Piston Skirt Oil Film Thickness by an Ultrasonic Means. SAE International, Technical Paper: 2006-01-0648, 2006

10. Dwyer-Joyce, R.S., Drinkwater, B.W., Donohoe, C.J.: The measurement of lubricant-film thickness using ultrasound. Proc. R. Soc. Lond. Ser. A: Math. Phys. Eng. Sci. 459(2032), 957-976 (2003)
11. Fitzsimons, B.: Introduction to the importance of fuel efficiency and role of the Encyclopaedic research project. IMechE Seminar: A Drive for fuel efficiency, Loughborough (2011)

12. Gohar, R., Rahnejat, H.: Fundamentals of Tribology. Imperial College Press, London (2008). ISBN-10: 1848161840

13. Hoshikawa, J., Kiminari, K., Miyamoto, K., Higashi, H.: A Study of Friction Reduction by 'Soft Skirt' Pisto. SAE International, Technical Paper: 2011-01-2120, 2011

14. Inagaki, H., Saito, A., Murakami, M., Konomi, T.: Measurement of oil film thickness distribution on piston surface using the fluorescence method: development of measurement system. JSME Int. J. Ser. B Fluids Therm. Eng. 40(3), 487-493 (1997)

15. Jalali-Vahid, D., Rahnejat, H., Jin, Z.M., Dowson, D.: Transient analysis of isothermal elastohydrodynamic of circular point contacts. Proc. IMechE Part C J. Mech. Eng. Sci. 215(10), 1159-1172 (2001)

16. Knoll, G.D., Peeken, H.J.: Hydrodynamic lubrication of piston skirts. Trans. ASME J. Lubr. Technol. 104, 504-509 (1982)

17. Kushwaha, M., Rahnejat, H.: Transient elastohydrodynamic lubrication of finite line conjunction of cam to follower concentrated contact. J. Phys. D Appl. Phys. 35(21), 2872-2890 (2002)

18. Li, D.F., Rohde, S.M., Ezzat, H.: An automotive piston lubrication model. ASLE Trans. 26(2), 151-160 (1983)

19. Littlefair, B., De la Cruz, M., Mills, R., Theodossiades, S., Howell-Smith, S., Rahnejat, H., Dwyer-Joyce, R.: Lubrication of a flexible piston skirt conjunction subjected to thermo-elastic deformation: a combined numerical and experimental investigation. Proc. IMechE Part J: J. Eng. Tribol. (2013). doi:10.1177/ 1350650113499555

20. McClure, F., Tian, T.: A Simplified Piston Secondary Motion Model Considering the Dynamics and Static Deformation of Piston Skirt and Cylinder Bore Internal Combustion Engines. SAE International, Technical Paper: 2008-01-1612, 2008

21. McClure, F.: Numerical Modelling of Piston Secondary Motion and Skirt Lubrication in Internal Combustion Engines. PhD thesis, Massachusetts Institute of Technology, USA, 2007

22. McFadden, P.D., Turnbull, S.R.: Dynamic analysis of piston secondary motion in an internal combustion engine under nonlubricated and fully flooded lubricated conditions. Proc. IMechE Part C: Eng. Sci. 225, 2575-2585 (2011)

23. Mills, R.S., Avan, E.Y., Dwyer-Joyce, R.S.: Piezoelectric sensors to monitor lubricant film thickness at piston-cylinder contacts in a fired engine. Proc. IMechE Part J: J. Eng. Trib. 227(2), 100-111 (2012)

24. Morris, N., Rahmani, R., Rahnejat, H., King, P.D., Fitzsimons, B.: Tribology of piston compression ring conjunction under transient thermal mixed regime of lubrication. Trib. Int. 59, 248-258 (2013)

25. Newmark, N.M.: A method of computation for structural dynamics. J. Eng. Mech. ASCE 85, 67-94 (1959)

26. Ning, L., Meng, X., Xie, Y.: Incorporation of deformation in a lubrication analysis for automotive piston skirt-liner system. Proc. IMechE Part J: J. Eng. Tribol. (2012). doi:10.1177/135065 0112466768

27. Offner, G., Priebsch, H.H.: Elastic body contact simulation for predicting piston slap induced noise in an IC engine. In: Rahnejat, H., Ebrahimi, M., Whalley, R. (eds.) Multi-Body Dynamics: Monitoring and Simulation Techniques-II, pp. 191-206. Loughborough, Professional Engineering Publishing (IMechE) (2000). ISBN 1-86058-258-3

28. Perera, M.S.M., Theodossiades, S., Rahnejat, H.: Elasto-multibody dynamics of internal combustion engines with tribological conjunctions. Proc. IMechE Part K: J. Multi-body Dyn. 224(3), 261-277 (2010)

29. Piao, Y., Gulwadi, S.: Numerical investigation of the effects of axial cylinder bore profiles on piston ring radial dynamics. Trans. ASME J. Eng. Gas Turbines Power 125, 1081-1089 (2003) 
30. Ragot, P., Rebbert, M.: Investigations of Crank Offset and its Influence on Piston and Piston Ring Friction Behavior Based on Simulation and Testing. SAE International Technical Paper: 2007-01-1248

31. Rahmani, R., Theodossiades, S., Rahnejat, H., Fitzsimons, B.: Transient elastohydrodynamic lubrication of rough new or worn piston compression ring conjunction with an out-of-round cylinder bore. Proc. IMechE Part J: J. Eng. Tribol. 226(4), 284-305 (2012)

32. Rahnejat, H.: Computational modelling of problems in contact dynamics. Eng. Anal. 2(4), 192-197 (1985)

33. Rahnejat, H.: Multi-body Dynamics: Vehicles, Machines and Mechanisms. Society of automotive Engineers (SAE), Warrendale, $\mathrm{Pa}$ and Professional Engineering Publishers (PEP), Bury St Edmunds, Joint Publishers, Bury St Edmunds (1998). ISBN 0768002699

34. Roelands, C.J.A.: Correlation aspects of the viscosity-temperature-pressure relationships of lubricant oils. Druk Kleine der A3-4 Groningen, 1966

35. Sadeghi, F.: Elastohydrodynamic lubrication. In: Rahnejat, H. (ed.) Tribology and Dynamics of Engine and Powertrain: Fundamentals, Applications and Future Trends. Woodhead Publishing, Cambridge (2010). ISBN 978-1-84569-361-9
36. Söchting, S., Sherrington, I.: The effect of load and viscosity on the minimum operating oil film thickness of piston-rings in internal combustion engines. Proc. Inst. Mech. Eng. Part J: J. Eng. Tribol. 223(3), 383-391 (2009)

37. Tattersall, H.G.: The ultrasonic pulse-echo technique as applied to adhesion testing. J. Phys. D Appl. Phys. 6, 819-832 (1973)

38. Taylor, R.I., Evans, P.G.: In-situ piston measurements. Proc. Inst. Mech. Eng. Part J: J. Eng. Tribol. 218(3), 185-200 (2004)

39. Timoshenko, S., Young, D., Weaver, W.: Vibration problems in engineering, 4th edn. Wiley, New York (1974)

40. Yang, P., Cui, J., Jin, Z.M., Dowson, D.: Transient elastohydrodynamic analysis of elliptical contacts. Part 2: thermal and Newtonian lubricant solution. Proc. IMechE Part J: J. Eng. Tribol. 219, 187-200 (2005)

41. Zhang, Z., Xie, Y., Zhang, X., Meng, X.: Analysis of piston secondary motion considering the variation on the system inertia. Proc. IMechE Part D: J. Automob. Eng. 223, 549-563 (2009)

42. Zhu, D., Cheng, H.S., Arai, T., Hamai, K.: A numerical analysis for piston skirts in mixed lubrication, part I: basic modelling. Trans. ASME J. Tribol. 114, 553-562 (1992)

43. Zhu, D., Cheng, H.S., Arai, T., Hamai, K.: A numerical analysis for piston skirts in mixed lubrication, part II: deformation considerations. Trans. ASME J. Tribol. 115, 125-133 (1993) 